Review Article

\title{
Brain-Derived Neurotrophic Factor, Depression, and Physical Activity: Making the Neuroplastic Connection
}

\author{
Cristy Phillips \\ Department of Physical Therapy, A-State, Jonesboro, AR, USA \\ Correspondence should be addressed to Cristy Phillips; cphillips@astate.edu
}

Received 14 April 2017; Accepted 18 July 2017; Published 8 August 2017

Academic Editor: Frank S. Hall

Copyright @ 2017 Cristy Phillips. This is an open access article distributed under the Creative Commons Attribution License, which permits unrestricted use, distribution, and reproduction in any medium, provided the original work is properly cited.

\begin{abstract}
Brain-derived neurotrophic factor (BDNF) is a neurotrophin that is vital to the survival, growth, and maintenance of neurons in key brain circuits involved in emotional and cognitive function. Convergent evidence indicates that neuroplastic mechanisms involving BDNF are deleteriously altered in major depressive disorder (MDD) and animal models of stress. Herein, clinical and preclinical evidence provided that stress-induced depressive pathology contributes to altered BDNF level and function in persons with MDD and, thereby, disruptions in neuroplasticity at the regional and circuit level. Conversely, effective therapeutics that mitigate depressive-related symptoms (e.g., antidepressants and physical activity) optimize BDNF in key brain regions, promote neuronal health and recovery of function in MDD-related circuits, and enhance pharmacotherapeutic response. A greater knowledge of the interrelationship between BDNF, depression, therapeutic mechanisms of action, and neuroplasticity is important as it necessarily precedes the derivation and deployment of more efficacious treatments.
\end{abstract}

\section{Introduction}

Major depressive disorder (MDD) is a leading cause of global disease burden that affects over 300 million persons worldwide [1-3]. Pathognomonic features of this complex mental illness include the persistence of one or more episodes of sadness or anhedonia in a two-week period, along with the manifestation of cognitive and somatic symptoms (e.g., changes in appetite, sleep patterns, energy level, concentration, or physical activity; feelings of worthlessness and guilt; and suicidal thoughts or behaviors) [4]. The disorder can consist of a single episode or several recurrent episodes. Direct and indirect costs of treating MDD in the United States exceed \$210 billion annually [5]. The high costs to individuals and society demand efficacious treatments, yet $30 \%$ of patients fail to respond to current pharmacotherapeutics and $70 \%$ do not achieve complete remission [6]. Disenchantment with the ability of extant drugs to mitigate symptoms in a significant proportion of persons, the undesirable side effects, and the high economic and social cost to society have prompted a diversification of the search for effective treatment options. Of the alternative therapeutics garnering attention, physical activity (PA) has shown clear and consistent promise for mitigating depressive neurobiology through mechanisms that involve brain-derived neurotrophin factor (BDNF).

Because it is important that clinicians and scientists understand the means by which PA can be used to optimize BDNF levels and mitigate pathophysiological substrates of depression, from both a self- and patient-education perspective, the aims of this review are to (1) explicate the putative neurobiological mechanisms involved in MDD and how trophic factors relate to those mechanisms, (2) review clinical and preclinical evidence of altered BDNF in persons with MDD, (3) discuss the relationship of BDNF to neuroplasticity, (4) discuss the effect of PA on BDNF, and (5) highlight current and future implications for clinicians and scientists.

\section{Neurobiology of Depression}

Neuroimaging studies of depression and surgical lesion studies that induce or mitigate depressive symptoms have been used to elucidate mood circuits $[7,8]$. Comprising these circuits are several brain structures and regions, particularly the dorsal prefrontal cortex, ventral prefrontal cortex, anterior cingulate gyrus, amygdala, hippocampus, striatum, and thalamus [9-11]. Several pathophysiological processes are 


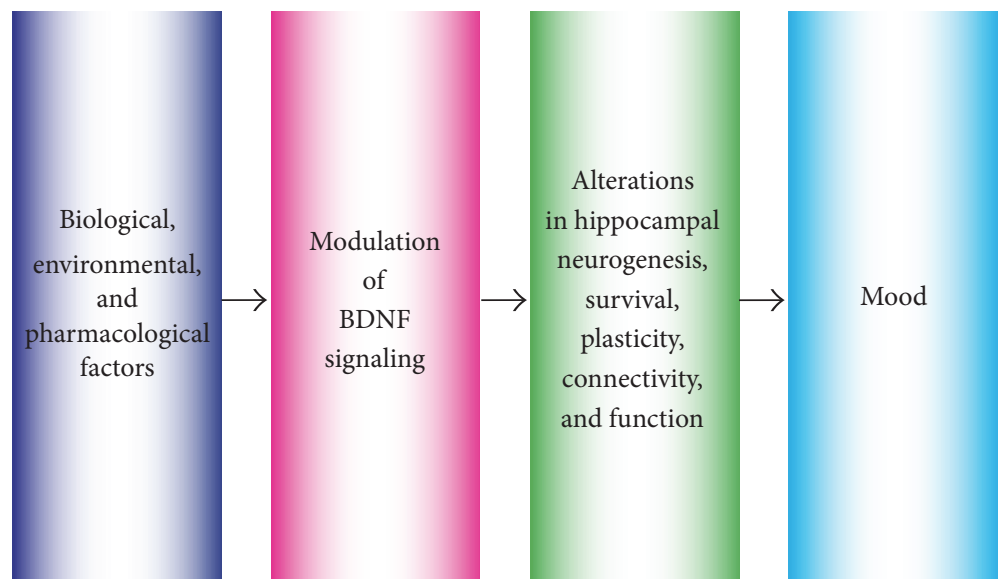

FIGURE 1: Endogenous and exogenous factors modulate BDNF levels to effectuate changes in the hippocampus and mood. Environmental stress-along with biological, genetic, and pharmacological factors-modulates BDNF levels and synaptic plasticity in various regions of the brain, including the hippocampus. Decrements in BDNF levels can confer vulnerability for hippocampal dysfunction and loss of emotional regulation. Conversely, antidepressant administration and voluntary PA optimize BDNF levels in the hippocampus and mitigate mood symptoms.

implicated in mood circuit and structure dysfunction $[7,12]$, including those related to genetic, epigenetic, and environmental factors. Results from a twin study suggest that the heritability of MDD is approximately 40\% [13]. Preclinical studies have implicated epigenetic mechanisms by demonstrating that maternal behavior alters the function of stressrelated genes [14] just as the administration of antidepressant drugs alters DNA regulation [15]. Other studies have shown that the depletion of neurotransmitters (e.g., dopamine, serotonin, and norepinephrine) contributes to depressive symptoms $[16,17]$ by altering glutamate and $\gamma$-aminobutyric acid (GABA) signaling. Accordingly, therapeutic agents were derived to either inhibit neuronal reuptake or inhibit degradation of monoamines in the synaptic cleft, actions aimed at increasing monoamine transmission. Yet monoamine depletion failed to produce depressive symptoms in persons who were healthy or worsen the severity of symptoms in persons with MDD [18]. Moreover, recent preclinical and clinical investigation demonstrated that ketamine, an NMDA receptor antagonist, induced rapid antidepressant effects through different mechanisms than monoamine reuptake inhibitors [18]. Subsequent study of signaling mechanisms that underlie the rapid antidepressant effects of ketamine has implicated BDNF and its ability to induce neuronal network alterations $[18,19]$.

The neurotrophic hypothesis of depression proposes that stress-related alterations in BDNF levels occur in key limbic structures to contribute to the pathogenic processes in MDD [19]. This notion is prefaced on evidence that neurotrophins are growth factors that play pivotal roles in the formation and plasticity of neuronal networks [20], and yet persons with MDD exhibit region-specific alterations in the level and function of BDNF. Upregulation of BDNF occurs in the amygdala and nucleus accumbens of persons with MDD whereas downregulation of BDNF occurs in the hippocampus and medial prefrontal cortex (mPFC) [21]. BDNF abnormalities also contribute to dysfunction of astrocytes and microglia in depression circuits. It has been shown that (1) persons with MDD exhibit decreased expression of glial fibrillary acidic protein and mRNA in the frontolimbic cortical region, (2) BDNF modulates glial function, and (3) antidepressant administration and deep brain stimulation mitigate glial deficits [22]. Finally, upregulation of BDNF occurs following chronic administration of antidepressants or voluntary participation in PA, consistent with the time course for the therapeutic action of antidepressants and PA [23]. Taken together, this evidence suggests that altered level and function of neurotrophins contributes to the atrophy, synaptic disconnection, and dysfunction of MD-related circuits $[24,25]$. Conversely, optimization of BDNF levels facilitates synaptic plasticity and remodeling, induction of long-term potentiation (LTP), modulation of gene expression for plasticity, resilience to neuronal insults [24-26], and alleviation of depressive symptoms [27] (see Figure 1). This evidence has led to concerted efforts to better understand the actions of BDNF and how these actions can be harnessed to maintain, repair, and reorganize damaged emotional and cognitive circuits, a central goal for MDD treatment and rehabilitation.

\section{Brain-Derived Neurotrophic Factor: Localization, Synthesis, Release, and Binding}

Neurotrophins are a closely related family of proteins in the brain that contributes to the survival, growth, and maintenance of neurons [28] and participate in a variety of learning and memory functions [29]. The mammalian neurotrophins include BDNF, nerve growth factor, neurotrophin 3, and neurotrophins 4-5. Undoubtedly, the majority of the literature linking neurotrophins with depression involves the study of BDNF. BDNF has proven to be one of the most highly inducible neurotrophins with $\mathrm{PA}$, prompting the focus on this neurotrophin herein. 
The synthesis of BDNF occurs in both the central and peripheral nervous system by target neurons under physiologic conditions and by astrocytes following injury, inflammation, or administration of antidepressants [30-32]. In the brain, neurons are considered a significant cellular source of BDNF, and synthesis occurs in regions that participate in emotional and cognitive function (e.g., hippocampus and frontal, parietal, and entorhinal areas). Gene expression studies in humans have revealed that central BDNF is highest in the cortex, hippocampus, amygdala, basal forebrain, dorsal vagal complex, hindbrain, and midbrain $[33,34]$. Several brain regions retrogradely transport BDNF from their projection areas. Raphe nuclei in the brainstem of rodents do not contain BDNF mRNA [35], but serotonergic neurons in these nuclei retrogradely transport BDNF from the frontal cortex, occipital cortex, entorhinal cortex, and amygdala (their projection areas) to their cell bodies [36, 37]. Noradrenergic neurons of the locus coeruleus retrogradely transport BDNF from the frontal and entorhinal cortex. It appears that nine different gene promoters induce the tissue-specific expression of 24 different BDNF transcripts, suggesting multilevel regulation of expression across brain regions [38]. The use of different promoters can facilitate the involvement of a myriad of transcription regulatory factors and mRNA-targeting signals, factors that shunt the translation of BDNF towards activated synaptic sites [39-41].

$\mathrm{BDNF}$ is synthesized as a precursor (pre-pro-BDNF protein) that results from cleavage of a $32 \mathrm{kDa}$ pro-BDNF protein. Pro-BDNF can be proteolytically cleaved intracellularly by enzymes (e.g., PC7, furin, and proconvertases) and secreted as the $14 \mathrm{kDa}$ mature form $[42,43]$ or it can be secreted as pro-BDNF and subsequently cleaved extracellularly by proteases (e.g., metalloproteinases and plasmin) [44]. Both forms of BDNF (pro-BDNF and mature) are sorted and packaged into vesicles for activity-dependent secretion $[36,45,46]$. Pro-BDNF can be internalized and stored by astrocytes and later released as the immature (pro-BDNF) or mature (BDNF) form [47].

Pro-BDNF mediates its biological actions through binding to low-affinity p75 neurotrophin receptors, whereas mature BDNF binds with higher-affinity tropomyosinrelated kinase family (Trk) receptors [48]. Once bound to its cognate receptors, BDNF is internalized along with its receptor and transported via retrograde axonal transport mechanisms to the soma wherein it can initiate a multiplicity of effects within the nucleus [49]. The functional importance of differential binding to either p75 or Trk receptors is underscored by their opposing effects. Proneurotrophin binding to p75 reduces spine complexity and density [50], induces long-term depression (LTD) [51], promotes neuronal cell death [52], and facilitates the resculpting of neuronal circuits [48]. These biological actions are accomplished via activation of a receptor complex that is composed of p75 and sortilin [52, 53]. In contrast, mature neurotrophin binding to Trk receptors increases cell survival and differentiation, dendritic spine complexity, long-term potentiation (LTP) [54, 55], synaptic plasticity [56], and the resculpting of networks [57]. Localization of TrkB receptors significantly increases at synaptic sites following neuronal activity [58].

\section{BDNF Abnormalities in Persons with Depression}

There is a well-established body of clinical evidence implicating the involvement of BDNF in the pathobiology of depression [59]. Peripheral reductions in mature BDNF in serum and plasma have been noted in persons with depression $[60,61]$ and in cases of suicide $[62,63]$, and psychosocial stress appears to exert a role in these decrements [64]. Findings from a recent meta-analysis and systematic review showed significantly lower levels of serum mature and pro-BDNF in antidepressant-free patients with MDD as compared to healthy controls [65]. Notwithstanding, serum levels of BDNF tend to normalize in response to several treatments (e.g., antidepressants [66], electroconvulsive therapy [67], and PA [68]).

Central reductions in BDNF in specific brain regions have been reported also. A postmortem study of persons with MDD reported decrements in BDNF protein in the hippocampus [19], along with smaller hippocampal volumes [69]. Dunham and colleagues reported a reduction of pro-BDNF in all layers of the right hippocampus in persons with depression [70]. Postmortem hippocampal samples taken from suicide completers exhibited increased mRNA for the p75 receptor [71], intimating that LTD and pruning may underlie hippocampal pathology. Thompson and colleagues reported a reduction of BDNF mRNA in layer II of the entorhinal cortex relative to controls [72]. BDNF levels were reduced in the hippocampus of postmortem samples taken from suicide completers [71, 73]. The activity of MAP kinase signaling, a major downstream signaling pathway associated with TrkB, was reduced in persons with depression $[74,75]$. Conversely, persons treated with antidepressant drugs exhibited increased BDNF expression and CREB in certain regions of the brain [76].

Further implicating BDNF with MDD are genetic $[73,77]$ studies demonstrating that depressive behavior is associated with altered BDNF functioning [78]. The Val66Met polymorphism in the $B D N F$ gene is a common singlenucleotide variant associated with $\operatorname{MDD}[79,80]$. It has an allele frequency of 20 to $30 \%$ in Caucasian populations [81]. The Val66Met polymorphism affects intracellular packaging of the pro-BDNF polypeptide and activity-dependent release [82, 83]. This polymorphism is associated with decreased hippocampal volume in healthy persons [84-86], persons with MDD [87], and persons suffering an adverse response to stress [88]. Also, it has been shown that persons who experience early-life stress and carry the Val66Met polymorphism exhibit significantly less grey matter in the subgenual anterior cingulate cortex [89] and are at increased risk for depression [90]. The Val66Met polymorphism is also a risk factor for geriatric depression [91] and has been shown to modulate antidepressant drug efficacy in Asians [92]. Thus, this naturally occurring genetic variant of the BDNF gene may contribute to a genetic predisposition for depressive disorder.

In addition to associations of the Met66 allele with decreased hippocampal size, other studies have demonstrated reduced hippocampal activation and poorer episodic 
memory $[83,93]$. The contribution of BDNF to mechanisms of learning and memory involves the modulation of synaptic transmission and plasticity $[94,95]$ and refinement of synaptic architecture [94, 96, 97] as well as activity-dependent transcription. It is generally held that activity-dependent transcription provides a mechanism by which neurons convert transient cellular changes to stable changes in brain function, particularly in memory formation. Increased calcium influx via voltage-gated $\mathrm{Ca}^{2+}$ channels and NMDA receptors is vital for neuronal plasticity mechanisms [98, 99]. NMDA receptor activation is particularly important for hippocampal synaptic plasticity [100] and modulation of BDNF [101], given that the latter determines the strength of existing synaptic connections and promotes the formation of new synapses. Together, this evidence suggests that alterations in BDNF function may affect activity-dependent plasticity in the hippocampus and thereby learning in memory and emotions in persons with MDD.

Knowledge of BDNF level and function is relevant for MDD research and treatment purposes for the several reasons listed.

(i) Altered BDNF function can contribute to an increased risk of depression and suicidal behavior [102].

(ii) With refinement of current knowledge, BDNF may eventually serve as a biomarker of depression and suicidal behavior in persons with depression and enhance diagnostic and treatment efforts [103, 104].

(iii) Treatment-induced normalization of BDNF may promote neural health and recovery of function from illness [105]. Additionally, the administration of BDNF-enhancing techniques (e.g., PA and transcranial stimulation) may enhance pharmacotherapeutic response [106].

\section{BDNF in Animal Models of Depression}

Stress is a well-known harbinger of depression in persons with genetic vulnerability [13, 107]. Evidence of the link between stress and depression has prompted investigators to derive animal research models of stress (e.g., immobilization, unpredictable chronic stress, foot shock, social isolation, social defeat, restraint, forced swim, and maternal deprivation) to determine a cause and effect relationship between pathology, interventions, BDNF, and depressive symptoms (for excellent reviews of depression metrics in animals, see [108-114]).

Preclinical studies have demonstrated that chronic stress and depressive-like symptoms are associated with reduced BDNF synthesis and activity of $\operatorname{TrkB}$ in the hippocampus and frontal cortex $[19,115,116]$, making it seem plausible that decreased levels of BDNF induce a state of increased vulnerability to stress and depression. Conversely, direct infusion of BDNF into the hippocampus or midbrain yields antidepressant-like effects [117, 118]. Other studies have shown that chronic administration of antidepressants increases BDNF mRNA protein in the hippocampus and cerebral cortex $[19,119-121]$, but these effects can be blocked in mice with a conditional knockout that reduces levels of BDNF in forebrain regions [122]. Similarly, chronic peripheral subcutaneous administration of BDNF to rats effectuated increased levels and signaling of BDNF along with antidepressant effects, that is, increased mobility in the forced swim test, increased sucrose consumption, decreased latency in the novelty-induced hypophagia test, and increased time spent in the open arms of an elevated plus maze [123]. Rodents overexpressing BDNF or TrkB also exhibit increased resistance and resilience to stress and depressive-related symptoms, that is, decreased immobility in forced swim [124, 125].

The robust effects between stress and BDNF levels are clearly apparent in the hippocampus in the subgranular zone [126]. Neurogenesis in the adult brain is a form of experience-dependent plasticity whereby stem cells within distinct regions (the subgranular zone of the hippocampus and subventricular zone) give rise to new neurons [127]. The 20,000,000 neurons generated over the course of a lifetime have different fates. Some newly born neurons migrate to the granule cell layer, develop a dendritic tree, and send their axon into the mossy fiber pathway $[127,128]$ to enhance the functional capacity of neural circuitry that is important for learning, memory, and emotional regulation [129-131] in an environmentally dependent manner [132]. Neurons that fail to accomplish this experience a different fate: death. Thus, the proliferation and survival of new neurons in the hippocampus is vitally important for persons with MDD [133], particularly given that the elevations in glucocorticoid levels that cooccur with MDs reduce levels of $\mathrm{BDNF}$ and rate of neurogenesis and induce the retraction of dendrites [64].

Fortunately, antidepressant drugs increase levels of BDNF in the hippocampus [19, 21], neurogenesis [134], and hippocampal cell survival rates [135]. The temporal profile of these effects is congruent with the temporal profile of clinical effectiveness of antidepressant drugs, suggesting a similarity between mechanisms [19, 35]. Other preclinical studies suggest that the degree of dendritic branching and the number of spines in hippocampal neurons increase following the restoration of BDNF levels [19, 35, 136-138]. Interestingly, selective deletion of the BDNF gene in the rodent hippocampus attenuates antidepressant efficacy as measured by the elevated plus maze, fear conditioning, sucrose preference, and forced swim tests [139]. Together, these findings suggest that altered expression of BDNF and dysregulation of neurogenesis in the hippocampus may effectuate maladaptive changes in neural networks that are implicated in MDD pathophysiology and, by corollary, that antidepressants may reverse these maladaptive changes.

Subsequent study has revealed that the relationship between BDNF and depressive symptoms is more nuanced in other brain regions. In contrast to the effects seen in the hippocampus, infusion of BDNF to the ventral tegmental/ nucleus accumbens area increased depression-like behavior (shorter latency to immobility in the forced swim test) [140] through mechanisms that may involve maladaptive learning. Berton and colleagues demonstrated that chronic 
stress increased BDNF levels within the nucleus accumbens [141], whereas virally mediated knockdown of BDNF in this region reduced social aversion following chronic social defeat [141], suggesting that increased BDNF in the ventral tegmental area and nucleus accumbens is positively associated with plasticity-induced aversive learning [142-144]. Finally, rodents with a knockdown of the BDNF gene in the ventral tegmental area consumed greater amounts of high-fat diet foods [145], whereas Goto-Kakizaki rats administered intracerebroventricular injections of BDNF exhibited suppressed feeding [146], a finding that underscores the modulating effects of BDNF on feeding behaviors and its interactions with the mesolimbic dopaminergic reward system [147].

Admittedly, central reductions in BDNF are not sufficient to produce depressive-like behaviors in all animals. Rather, reductions of BDNF appear to increase susceptibility to the deleterious effects of stress: exposure of BDNF heterozygous knockout mice to stress induces depressive-like behavior, as does the blockade of BDNF-TrkB signaling following stress [148]. These studies suggest that the anti- or prodepressive effects of BDNF depend upon the brain region affected and offer evidence that selectively targeting BDNF levels in key brain regions may benefit patients affected by MDs. These studies also demonstrate that the effects of BDNF are regionand circuit-specific and cannot be extended arbitrarily to other brain regions.

\section{BDNF, Plasticity, and Neuroprotection in MDD}

It has been proposed that BDNF signaling is a prime mediator of activity-dependent neural plasticity and the resculpting of MD-related circuits [149-151]. Neuroimaging studies have revealed functional deficits in cognitive and affective processing during the early phases of illness [152-155], changes that become increasingly impaired with illness progression [156], and the emergence of structural impairments in the frontal cortex and hippocampus [157-160]. Together, the functional and structural deficits disrupt cognitive and affective regulation that is dependent upon circuit-level integrity of the prefrontal-thalamo-limbic and limbicstriatal-pallidal-thalamic systems [161]. By corollary, circuit level disruption can impede future learning [162]. Cortical regions (e.g., dorsolateral prefrontal cortex $[163,164]$ and anterior cingulate cortex [165]) comprise the cognitive control network, whereas the subcortical regions (e.g., hippocampus [166], amygdala [167], parahippocampal gyrus [168], caudate nucleus [169], posterior cingulate cortex [168], and thalamus [170]) comprise the affective processing network. Persons who are depressed exhibit impairments in the cognitive control network as evidenced by their inability to disengage from negative stimuli, a task that requires topdown regulation by cortical regions $[164,171]$. They may also exhibit impairments in the affective control network as evidenced by hyperactivity of the amygdala $[156,172]$ and hippocampus [163] to negative stimuli and recall.

The impairments in structure and function in these areas and circuits putatively arise from a myriad of contributing factors, including altered trophic factor level and function, neurotransmitter level and function, stress regulation, peroxisome proliferator-activated receptor $\mathrm{C}$ coactivator alpha, neurogenesis, immune function, antioxidant defense, circadian rhythms, epigenetic modifications, and maintenance of telomere length [173]. Within this context, decrements in BDNF are not sufficient to effectuate depression in humans per se. Rather, adequate levels of BDNF effectuate activitydependent neuronal plasticity that is requisite for the maintenance of basal neuronal and circuit function [174] and for making adaptive responses to endogenous and exogenous stressor challenges [27, 175], particularly during chronic stress [88] and depressive states [87].

Inherent to the depressive state is the inability to return to normal circuit function following the abatement of stressful situations (either psychological or physical in nature), a phenomenon that likely reflects reduced plasticity. Hippocampal atrophy and disconnected brain circuits become increasingly resistant to change in the absence of exogenous interventions that promote recovery. Part of this resistance is the result of the disconnection and loss of function that occurs $[19,24,176,177]$ secondary to synaptic decrements [178, 179].

Synapses typically exhibit plasticity, a state where their function and structure are modified in response to activity and factors in the cellular milieu. LTP is one form of functional synaptic plasticity, wherein connections between synapses become strengthened with activity, a process that is fundamental to learning and memory [180]. Yet, requisite for the strengthening of LTP is the presence of mature BDNF [181]. LTD is another form of functional plasticity, where a set of synapses display a reduced capacity to elicit a response in one another, a process that is vital to forgetting [182]. Requisite for LTD are adequate levels of pro-BDNF [181]. Working in concert, LTP and LTD regulate homeostatic plasticity and the function of neuronal circuits $[149,183]$ in emotional circuits. This regulation is accomplished by the ability of high-frequency (but not low-frequency) stimulation to induce the secretion of tissue plasminogen activator, a protease that converts extracellular pro-BDNF to mature BDNF [181]. Not surprisingly, the study of hippocampi in persons with MDs has revealed that decreased volumes are positively associated with symptom severity, duration, and treatment outcomes [184-187].

Fortunately, antidepressant drug administration enhances synaptic turnover [188-190], increases synaptic plasticity gene activation [191], and promotes functional connectivity in the hippocampus [192] following stress, processes that are dependent upon TrkB signaling [188]. Also, antidepressant administration increases phosphorylation of TrkB receptors in the rodent hippocampus and cortex within hours [193, 194] and increases the translocation of TrkB receptors to synaptic sites [195]. Via phosphorylation of BDNF and other mechanisms, antidepressant drugs appear to reactivate neuroplasticity.

Maya Vetencourt and colleagues previously reported that chronic administration of fluoxetine, at a dosage that produced serum fluoxetine levels within the therapeutic range in humans, reinstated ocular dominance plasticity in adulthood and promoted visual recovery in amblyopic adult 
animals. These effects were accompanied by reduced intracortical inhibition and increased BDNF expression in the visual cortex [196]. Similarly, direct infusion of BDNF into the visual cortex recapitulated the effects of fluoxetine [196], suggesting that the antidepressant drug reinstated critical period-like plasticity in the visual cortex [197].

Kobayashi and colleagues demonstrated that chronic treatment of adult mice with fluoxetine greatly reduced expression of calbindin, a marker for mature granule cells in the hippocampus. Additionally, chronic administration of fluoxetine induced active membrane properties that resembled immature granule cells and concomitantly reduced the synaptic facilitation that is characteristic of mature dentate-to-CA3 signal transmission, suggesting that the drug reversed the established state of neuronal maturation in the adult hippocampus [198].

Karpova and colleagues investigated the effects of antidepressants on behavioral experience by using a fearconditioning and fear-extinction paradigm in rodents. They combined extinction training with chronic fluoxetine and induced an enduring loss of conditioned fear memory in adult animals, an effect that could not be produced without the drug. Strikingly, fluoxetine administration effectuated synaptic plasticity and facilitated the conversion of the fear memory circuitry to an immature state, effects that were mediated by BDNF. The authors concluded that fluoxetineinduced plasticity permits fear erasure by extinction-guided remodeling of the memory circuitry, suggesting that antidepressant drugs may be used to prime plasticity in circuits prior to psychological rehabilitation to facilitate the reorganization and proper function of MDD networks [199].

In another study, Chollet and colleagues administered patients who suffered a stroke add-on fluoxetine to physical therapy. The results of their double-blind, placebocontrolled trial demonstrated that persons who received early prescription of fluoxetine with physical therapy had enhanced motor recovery after 3 months [200].

These findings support the notion that antidepressant drug mechanisms involve the reactivation of neuroplasticity and facilitation of functional reorganization of the neuronal network when accompanied by environmental enrichment $[175,201]$. By corollary, they underscore the importance of resolving stressful situations that initially induced functional and structural impairment in mood-related circuits and of deriving biomarkers that facilitate earlier detection and rehabilitation before the illness gains a strong foothold [202]. Also, this evidence highlights a critical unmet need for new antidepressant therapeutics that exert faster onset of action and greater efficacy. Accordingly, a multiplicity of preclinical and clinical investigations has aimed to understand how therapeutics can be used to harness homeostatic mechanisms that regulate neurotrophin release and function to mitigate MDD-related disease, particularly aerobic PA [129, 173, 203].

\section{Physical Activity, BDNF, and Neuroplasticity}

Convergent evidence demonstrates the positive effects of PA in persons with MDD. PA refers to activities that require energy expenditure and involve bodily movements produced by skeletal muscles [204]. Exercise is a subcategory of PA that entails purposeful, planned, and structured endeavors undertaken to improve physical fitness or skill level [204]. Evidence suggests that PA reduces the risk for MDD [205, 206], mitigates symptoms [207], facilitates recovery [208, 209], lowers the incidence of relapse [210,211], and decreases overall caregiver burden [212]. Undoubtedly, many of the positive effects of PA on brain health and function derive from its ability to optimize central levels of BDNF, particularly in the hippocampus [130].

Preclinical work demonstrates that chronic PA upregulates the expression of BDNF in the hippocampus of rodents for days [116, 213]. Concomitantly, endurance exercise induces elevations of muscle-derived proteins [proliferatoractivated receptors (PGC-1 $\alpha$ ) and FNDC5] that regulate BDNF expression in the rodent hippocampus. The ability of PA to modulate changes in BDNF and PGC- $1 \alpha$ is relevant for stress-induced depression given their interaction with neuroinflammatory and neuroplasticity pathways [214] via alterations in tryptophan degradation [204, 215] and $5-\mathrm{HT}_{1 \mathrm{~A}}$ receptor activation [216].

A bevy of other work underscores the inextricable relationship between PA, BDNF level optimization, and downstream factors. PA optimizes neurotransmitter system level and function (e.g., glutamate, GABA, serotonin, dopamine, and noradrenaline) [173]. In turn, changes in neurotransmission mediate changes in BDNF gene expression in various brain regions (e.g., hippocampus, nucleus accumbens, and amygdala) [217]. Robust preclinical and clinical work demonstrates that PA increases neurogenesis and plasticity via BDNF-dependent mechanisms, particularly when paired with environmental enrichment [173, 218]. Other work demonstrates that PA attenuates the inflammatory process and induces a more resilient stress response [173]. The ability of PA to mitigate HPA dysregulation is especially important for preventing hippocampal atrophy $[219,220]$ in persons with affective disorders [221] because chronic exposure of hippocampal neurons to elevated glucocorticoid levels induces a retraction of dendrites and reduction of dendritic spines [222].

Emerging preclinical evidence suggests that PA can mitigate the astrocytic dysfunction seen in MDD. Early work in rodents demonstrated that ablation of astrocytes effectuated a reduction of dentate granule cell density and glutamate transporter expression, changes that negate the ability of these cells to effectively remove glutamate excess from the synaptic milieu [223]. Later work demonstrated that chronic stress reduced the number of astrocytic projections in rodents, whereas environmental enrichment increased the number of astrocytic projections [224], a significant finding given that the extent of astrocyte projections is a marker of well-being in these cells. Bolstering the notion of a link between astrocytic function and BDNF is a preclinical work showing that BDNF infusion attenuates hippocampal glial fibrillary acidic level reductions that were a consequence of chronic unpredictable stress [225]. More recent work showed that rodents exposed to long-term PA (5 days per week $\times 4$ weeks) demonstrate increased BDNF synthesis and release 
TABLE 1: Effects of physical activity on brain-derived neurotrophic factor (BDNF).

\begin{tabular}{|c|c|c|c|}
\hline Reference & Sample & Treatment & Assessment outcome \\
\hline$[233]$ & 13 young, healthy men & $\begin{array}{l}\text { Moderate-intensity aerobic PA } 4 \mathrm{~d} / \mathrm{wk} \\
\text { for } 5 \mathrm{wks}\end{array}$ & $\uparrow$ plasma BDNF \\
\hline [234] & 7 healthy, sedentary males & Aerobic PA $7 \mathrm{~d} /$ wk for 12 wks & $\uparrow$ plasma BDNF \\
\hline [238] & 60 older adults & Aerobic PA $3 \mathrm{~d} / \mathrm{wk}$ for $60 \mathrm{wks}$ & $\uparrow \mathrm{BDNF}$ and $\uparrow$ hippocampal volume \\
\hline$[236]$ & 47 healthy, sedentary males & Aerobic PA $3 \mathrm{~d} / \mathrm{wk}$ for $5 \mathrm{wks}$ & $\begin{array}{l}\uparrow \text { serum BDNF following PA and } \uparrow \text { memory } \\
\text { on face name matching }\end{array}$ \\
\hline [235] & 62 healthy, sedentary males & Moderate-intensity aerobic PA for 2 wks & $\begin{array}{l}\uparrow \text { serum BDNF following PA and } \uparrow \text { memory } \\
\text { on face name matching }\end{array}$ \\
\hline [247] & $\begin{array}{l}104 \text { persons with partial } \\
\text { response to antidepressants }\end{array}$ & $\begin{array}{c}\text { Add-on high }(16 \mathrm{kcal} / \mathrm{kg} / \text { week }) \text { or low } \\
(4 \mathrm{KKW}) \\
\text { PA for } 12 \text { wks to standard depression } \\
\text { care }\end{array}$ & $\begin{array}{c}\text { Persons entering with } \uparrow \text { BDNF levels exhibited } \uparrow \\
\text { rate of response to antidepressants }\end{array}$ \\
\hline [248] & 15 severely depressed adults & $\begin{array}{l}\text { Add-on aerobic PA } 16 \mathrm{kcal} / \mathrm{kg} / \text { week for } \\
3 \mathrm{~d} / \mathrm{wk} \\
\text { for } 3 \text { wks to standard care for depression } \\
\text { or medication-only group }\end{array}$ & $\begin{array}{l}\text { Similar } \uparrow \text { in BDNF in aerobic PA and } \\
\text { medication-only group, but } \downarrow \text { in oxidative } \\
\text { stress markers seen only in PA group }\end{array}$ \\
\hline
\end{tabular}

in the dentate gyrus along with altered orientation and morphology of astrocytes, effects that are TrkB-signaling dependent [226]. The latter findings suggest that PA-induced changes in astrocytic projection length and density might enhance glutamate clearance from the synapse and mitigate glutamate excitotoxicity in models of MDD, a notion that awaits further study.

Some evidence suggests a synergistic effect of PA and restricted dietary intake on BDNF upregulation. Alomari and colleagues examined the effects of aerobic PA (voluntary wheel running or forced swimming) plus caloric restriction versus dietary restriction alone on BDNF and learning and memory in rodents. Their results demonstrated that the combination of voluntary PA and caloric restriction effectuated greater increases in BDNF levels in the hippocampus, even though improvements in spatial learning and memory occurred in both the combination and dietary restriction groups [227]. Thus, it seems plausible that multidomain treatments such as PA and dietary modification may be particularly beneficial in persons with MDD who exhibit stress-induced decrements in central and peripheral BDNF levels and carry gene-copy-number variants in the BDNF gene.

Carriers of the BDNF Val66Met polymorphism exhibit decreased activity-dependent secretion in comparison to $\mathrm{Val} / \mathrm{Val}$ carriers, although the level of constitutive secretion of BDNF protein in hippocampal neurons remains the same [83]. Decreased activity-dependent secretion from the neurons of BDNF Met carriers is functionally significant because most BDNF protein is released from the activity-dependent pathway $[83,228]$. The fact that PA modulates BDNF levels and symptoms of depression $[229,230]$ suggests that BDNF gene interactions with PA may influence depressive symptoms [231]. Bolstering this notion is recent work showing that the BDNF polymorphism moderates the association between PA and depressive symptoms. Higher levels of PA were protective against depressive symptoms for girls with the BDNF Met allele, but not for girls with the Val/Val polymorphism [232].

Further elucidating the association between PA and BDNF are clinical investigations of brain structure and function (see Table 1). These studies reaffirm that chronic aerobic exercise increases peripheral levels of BDNF [233-236], blood volume in the dentate gyrus [237], grey matter in the prefrontal and cingulate cortex [235], size of the right and left hippocampus [238], and memory performance [235, 236] in humans. Encouragingly, increases in hippocampal size are correlated with increased spatial memory performance in persons who are healthy and experiencing neurodegenerative changes [238], suggesting that PA might mitigate the cognitive deficits experienced in MDD. Moderate to high training intensity PA appears requisite for maximal PA effects [239, 240]. Clinical studies have demonstrated that acute aerobic PA at $85 \%$ of maximal capacity increased plasma BDNF levels, which is important because plasma BDNF levels are linked to alterations in BDNF levels [241, 242], synaptic plasticity, and learning ability [243], whereas blockade of BDNF on TrkB receptors reduced the effects of PA on synaptic plasticity [244].

Parallel studies have investigated the relationship of PA, BDNF, and depressive symptoms. It has been shown that PA increases BDNF in unmedicated patients with MDD [245] and elderly persons with remitted depression [246]. Examining the effects of exercise augmentation $(16 \mathrm{kcal} / \mathrm{kg} /$ week $\times 12$ weeks) in persons who experienced a partial response to antidepressants, Toups and colleagues found that persons with higher BDNF levels experienced more rapid symptom relief, suggesting that pretreatments with exercise might improve antidepressant efficacy [247]. Schuch and colleagues investigated the effects of add-on PA $(16.5 \mathrm{kcal} / \mathrm{kg} /$ week of aerobic exercise $3 \times$ per week for approximately 3 weeks) with treatment as usual. They found no additional increase of BDNF in the exercise plus medication group relative to the medication-only group, suggesting a plateau 
effect of antidepressant drugs on BDNF levels in persons with depression [248]. What remains to be determined is whether this plateau effect exists in carriers of the Met allele.

While it is known that PA increases circulating BDNF levels in healthy humans [249] and that BDNF is vitally important for maintaining affective and cognitive circuit function during health and disease, the source of these increases remains unclear. Some have proposed that platelets are the origin of serum BDNF following exercise [250], but BDNF is also increased in plasma samples, a finding that implicates other sources. Krabbe and colleagues demonstrated cerebral output of BDNF in healthy humans at rest [251], suggesting that exercise-induced alterations in plasma BDNF levels reflect altered release of BDNF from the brain [252]. Exploring the latter notion further, Rasmussen and colleagues used arterial-to-internal jugular venous measurement differences to analyze the contribution of the human brain to plasma BDNF levels at rest and during prolonged whole-body exercise. Their results show that the brain is a significant source of BDNF production at rest and during prolonged exercise, contributing approximately threequarters of the BDNF to venous circulation [253]. Part of the increase in central BDNF may be a consequence of activated platelets in the cerebral circulation [254] or activity-dependent function in other brain structures (e.g., hippocampus and cortex) [253].

These results suggest that PA effectuates central neuroplastic adaptations via optimization of BDNF levels. The ability of PA to enhance BDNF release and function in the synapse, promote dendritic spine integrity, and activate other cellular pathways that contribute to plasticity $[19,24,255]$ is vital for homeostatic processes that are necessary for the maintenance, repair, and reorganization of circuits damaged during depression, effects that recapitulate those of antidepressant drugs. While it remains to be determined whether PA can reactivate neuroplasticity, preliminary work by Eadie and colleagues has demonstrated that long-term PA significantly increased total length and complexity of dendrites, increased the spine density on dendrites, and induced a more immature state of dentate granule cells [137].

\section{Conclusions and Future Directions}

The derivation of an effective treatment for MDD represents an unmet goal. Notwithstanding, considerable progress has been made in better understanding the pathobiological features and processes that contribute to the structural, functional, and circuit disruptions that are endemic to MDD. Herein, biomedical evidence demonstrated that stressinduced depressive pathology contributes to altered BDNF level and function in persons with MDD and, thereby, disruptions in neuroplasticity at the regional and circuit level. By corollary, effective therapeutics that mitigate depressiverelated symptoms (e.g., antidepressants and physical activity) will optimize BDNF in key brain regions to promote neuronal health and recovery of function in MDD-related circuits. A better ability to deploy therapeutics that optimize $\mathrm{BDNF}$ is needed given evidence that intervention in neurodegenerative processes is more likely to achieve disease modification, while ones deployed later demonstrate a significant but more limited effect after the emergence of neuronal degeneration [256].

Clearly, there is an urgent need to identify how PA can best be translated operationally to influence the health and wellness of brain structure and function [173], particularly by optimizing neuroplasticity mechanisms. This challenge will necessarily entail a better understanding of how the optimum mode, intensity, and duration of PA might alter MDDrelated symptoms and pathology. Several studies suggest that exercise interventions that combine multiple modalities (e.g., aerobic and strength-training activities) are more effective at enhancing emotional and cognitive health in humans in comparison to those that emphasize aerobic activities alone. Colcombe and Kramer reported that persons who participated in aerobic and strength-training activities exhibited higher gains in cognition in comparison to those who participated in aerobic activities alone [257]. Smith and colleagues reported that interventions that consisted of aerobic and strength-training activities improved attention, processing speed, and working memory to a greater extent than aerobic exercise alone in both healthy individuals and those with neurodegeneration [258], an effect putatively linked to alterations in hippocampal volume $[238,259]$. Supporting the latter notion is evidence that decrements in hippocampal size are linked to neurodegenerative progression, whereas the reversal of neurodegenerative progression has been linked to improvements in hippocampal volume [219, 220]. Indeed, aerobic exercise of moderate intensity for 12 months improved memory and hippocampal size in healthy older adults, effectively reversing age-related loss of volume by one to two years [238]. Directly applying the aforementioned, Makizako and colleagues demonstrated that hippocampal volume was directly linked to improved memory in humans and that greater durations of moderate PA could effectuate greater increases in hippocampal volume and memory [259].

Altogether, the data presented here suggests that moderate $\mathrm{PA}-\mathrm{a}$ target that is practical, well tolerated, and likely to optimize exercise adherence-optimizes BDNF and plasticity, particularly in persons with depression. PA's relative low-risk profile, ease of implementation, and absence of side effects [260] have led to the incorporation of PA into basic clinical management protocols for MDs [261, 262]. Undoubtedly, future efforts to improve population health should consider the ability of lifestyle factors to prevent and treat mental disorders [263] by optimization of neuroplasticity substrates, particularly when coupled with rehabilitation.

\section{Abbreviations}

BDNF: Brain-derived neurotrophic factor

GABA: $\quad \gamma$-Aminobutyric acid

LTD: $\quad$ Long-term depression

LTP: $\quad$ Long-term potentiation

MDD: $\quad$ Major depressive disorder

NMDA: N-Methyl-D-aspartate

PA: $\quad$ Physical activity

TrkB receptors: Tropomyosin receptor kinase B. 


\section{Conflicts of Interest}

The author declares that she has no conflicts of interest.

\section{Acknowledgments}

The author would like to thank Ms. Cindy Ferrell for professional graphic work.

\section{References}

[1] World Health Organization, "Depression: let's talk," Mental Disorders Fact Sheet Online, 2017.

[2] J. L. Abel and E. F. Rissman, "Running-induced epigenetic and gene expression changes in the adolescent brain," International Journal of Developmental Neuroscience, vol. 31, no. 6, pp. 382-390, 2013.

[3] A. J. Ferrari, F. J. Charlson, R. E. Norman et al., "The epidemiological modelling of major depressive disorder: application for the Global Burden of Disease Study 2010," PLoS One, vol. 8, no. 7, article e69637, 2013.

[4] Association AP, Diagnostic and Statistical Manual of Mental Disorders, Washington, DC, 2013.

[5] P. E. Greenberg, "The Growing Economic Burden of Depression in the U.S.," Scientific America, 2015, webpage, accessed on April 12, 2017.

[6] S. Kulkarni, A. Dhir, and K. K. Akula, "Potentials of curcumin as an antidepressant," Scientific World Journal, vol. 9, pp. 1233-1241, 2009.

[7] J. L. Price and W. C. Drevets, "Neural circuits underlying the pathophysiology of mood disorders," Trends in Cognitive Sciences, vol. 16, no. 1, pp. 61-71, 2012.

[8] J. C. Masdeu, "Neuroimaging in psychiatric disorders," Neurotherapeutics, vol. 8, no. 1, pp. 93-102, 2011.

[9] S. Kito, T. Hasegawa, and Y. Koga, "Cerebral blood flow ratio of the dorsolateral prefrontal cortex to the ventromedial prefrontal cortex as a potential predictor of treatment response to transcranial magnetic stimulation in depression," Brain Stimulation, vol. 5, no. 4, pp. 547-553, 2012.

[10] K. Willeumier, D. V. Taylor, and D. G. Amen, "Decreased cerebral blood flow in the limbic and prefrontal cortex using SPECT imaging in a cohort of completed suicides," Translational Psychiatry, vol. 1, article e28, 2011.

[11] Y. Nagafusa, N. Okamoto, K. Sakamoto et al., "Assessment of cerebral blood flow findings using 99mTc-ECD singlephoton emission computed tomography in patients diagnosed with major depressive disorder," Journal of Affective Disorders, vol. 140, no. 3, pp. 296-299, 2012.

[12] W. C. Drevets, J. Savitz, and M. Trimble, "The subgenual anterior cingulate cortex in mood disorders," CNS Spectrums, vol. 13, no. 8, pp. 663-681, 2008.

[13] K. S. Kendler, M. Gatz, C. O. Gardner, and N. L. Pedersen, "A Swedish national twin study of lifetime major depression," The American Journal of Psychiatry, vol. 163, no. 1, pp. 109-114, 2006.

[14] I. C. Weaver, N. Cervoni, F. A. Champagne et al., "Epigenetic programming by maternal behavior," Nature Neuroscience, vol. 7, no. 8, pp. 847-854, 2004.

[15] R. Massart, R. Mongeau, and L. Lanfumey, "Beyond the monoaminergic hypothesis: neuroplasticity and epigenetic changes in a transgenic mouse model of depression,"
Philosophical Transactions of the Royal Society of London Series B, Biological Sciences, vol. 367, no. 1601, pp. 24852494, 2012.

[16] R. M. Hirschfeld, "History and evolution of the monoamine hypothesis of depression," The Journal of Clinical Psychiatry, vol. 61, Supplement 6, pp. 4-6, 2000.

[17] P. L. Delgado, "Depression: the case for a monoamine deficiency," The Journal of Clinical Psychiatry, vol. 61, Supplement 6, pp. 7-11, 2000.

[18] M. Ghasemi, C. Phillips, L. Trillo, Z. De Miguel, D. Das, and A. Salehi, "The role of NMDA receptors in the pathophysiology and treatment of mood disorders," Neuroscience and Biobehavioral Reviews, vol. 47, pp. 336-358, 2014.

[19] R. S. Duman and L. M. Monteggia, "A neurotrophic model for stress-related mood disorders," Biological Psychiatry, vol. 59, no. 12, pp. 1116-1127, 2006.

[20] E. J. Huang and L. F. Reichardt, "Trk receptors: roles in neuronal signal transduction," Annual Review of Biochemistry, vol. 72, pp. 609-642, 2003.

[21] A. E. Autry and L. M. Monteggia, "Brain-derived neurotrophic factor and neuropsychiatric disorders," Pharmacological Reviews, vol. 64, no. 2, pp. 238-258, 2012.

[22] D. Rial, C. Lemos, H. Pinheiro et al., "Depression as a glialbased synaptic dysfunction," Frontiers in Cellular Neuroscience, vol. 9, p. 521, 2015.

[23] A. Russo-Neustadt, R. C. Beard, and C. W. Cotman, "Exercise, antidepressant medications, and enhanced brain derived neurotrophic factor expression," Neuropsychopharmacology, vol. 21, no. 5, pp. 679-682, 1999.

[24] V. Krishnan and E. J. Nestler, "The molecular neurobiology of depression," Nature, vol. 455, no. 7215, pp. 894-902, 2008.

[25] R. S. Duman, "Pathophysiology of depression and innovative treatments: remodeling glutamatergic synaptic connections," Dialogues in Clinical Neuroscience, vol. 16, no. 1, pp. 11-27, 2014.

[26] A. L. Teixeira, I. G. Barbosa, B. S. Diniz, and A. Kummer, "Circulating levels of brain-derived neurotrophic factor: correlation with mood, cognition and motor function," Biomarkers in Medicine, vol. 4, no. 6, pp. 871-887, 2010.

[27] R. S. Duman, "Pathophysiology of depression: the concept of synaptic plasticity," European Psychiatry, vol. 17, Supplement 3, pp. 306-310, 2002.

[28] K. K. Cowansage, J. E. LeDoux, and M. H. Monfils, "Brainderived neurotrophic factor: a dynamic gatekeeper of neural plasticity," Current Molecular Pharmacology, vol. 3, no. 1, pp. 12-29, 2010.

[29] J. E. Ahlskog, Y. E. Geda, N. R. Graff-Radford, and R. C. Petersen, "Physical exercise as a preventive or diseasemodifying treatment of dementia and brain aging," Mayo Clinic Proceedings, vol. 86, no. 9, pp. 876-884, 2011.

[30] A. Giralt, H. C. Friedman, B. Caneda-Ferrón et al., "BDNF regulation under GFAP promoter provides engineered astrocytes as a new approach for long-term protection in Huntington's disease," Gene Therapy, vol. 17, no. 10, pp. 1294-1308, 2010.

[31] J. S. Rudge, E. M. Pasnikowski, P. Holst, and R. M. Lindsay, "Changes in neurotrophic factor expression and receptor activation following exposure of hippocampal neuron/ astrocyte cocultures to kainic acid," The Journal of Neuroscience, vol. 15, no. 10, pp. 6856-6867, 1995. 
[32] J. Prickaerts, J. De Vry, J. Boere et al., "Differential BDNF responses of triple versus dual reuptake inhibition in neuronal and astrocytoma cells as well as in rat hippocampus and prefrontal cortex," Journal of Molecular Neuroscience, vol. 48, no. 1, pp. 167-175, 2012.

[33] K. Marosi and M. P. Mattson, "BDNF mediates adaptive brain and body responses to energetic challenges," Trends in Endocrinology and Metabolism, vol. 25, no. 2, pp. 89-98, 2014.

[34] A. Salehi, J. D. Delcroix, P. V. Belichenko et al., "Increased app expression in a mouse model of Down's syndrome disrupts NGF transport and causes cholinergic neuron degeneration," Neuron, vol. 51, no. 1, pp. 29-42, 2006.

[35] H. D. Schmidt and R. S. Duman, "The role of neurotrophic factors in adult hippocampal neurogenesis, antidepressant treatments and animal models of depressive-like behavior," Behavioural Pharmacology, vol. 18, no. 5-6, pp. 391-418, 2007.

[36] A. Salehi, J. D. Delcroix, and W. C. Mobley, "Traffic at the intersection of neurotrophic factor signaling and neurodegeneration," Trends in Neurosciences, vol. 26, no. 2, pp. 7380, 2003.

[37] E. J. Mufson, J. S. Kroin, T. J. Sendera, and T. Sobreviela, "Distribution and retrograde transport of trophic factors in the central nervous system: functional implications for the treatment of neurodegenerative diseases," Progress in Neurobiology, vol. 57, no. 4, pp. 451-484, 1999.

[38] C. Cunha, R. Brambilla, and K. L. Thomas, "A simple role for BDNF in learning and memory?" Frontiers in Molecular Neuroscience, vol. 3, p. 1, 2010.

[39] O. Steward and E. M. Schuman, "Protein synthesis at synaptic sites on dendrites," Annual Review of Neuroscience, vol. 24, pp. 299-325, 2001.

[40] O. Steward and P. F. Worley, "A cellular mechanism for targeting newly synthesized mRNAs to synaptic sites on dendrites," Proceedings of the National Academy of Sciences of the United States of America, vol. 98, no. 13, pp. 7062-7068, 2001.

[41] Q. R. Liu, D. Walther, T. Drgon et al., "Human brain derived neurotrophic factor (BDNF) genes, splicing patterns, and assessments of associations with substance abuse and Parkinson's disease," American Journal of Medical Genetics Part B, Neuropsychiatric Genetics, vol. 134B, no. 1, pp. 93-103, 2005.

[42] N. G. Seidah, S. Benjannet, S. Pareek, M. Chretien, and R. A. Murphy, "Cellular processing of the neurotrophin precursors of NT3 and BDNF by the mammalian proprotein convertases," FEBS Letters, vol. 379, no. 3, pp. 247-250, 1996.

[43] W. C. Wetsel, R. M. Rodriguiz, J. Guillemot et al., "Disruption of the expression of the proprotein convertase PC7 reduces BDNF production and affects learning and memory in mice," Proceedings of the National Academy of Sciences of the United States of America, vol. 110, no. 43, pp. 17362-17367, 2013.

[44] K. Deinhardt and M. V. Chao, "Shaping neurons: long and short range effects of mature and proBDNF signalling upon neuronal structure," Neuropharmacology, vol. 76, Part C, pp. 603-609, 2014.

[45] G. Aicardi, E. Argilli, S. Cappello et al., "Induction of long-term potentiation and depression is reflected by corresponding changes in secretion of endogenous brain-derived neurotrophic factor," Proceedings of the National Academy of Sciences of the United States of America, vol. 101, no. 44, pp. 15788-15792, 2004.
[46] I. J. Lever, E. J. Bradbury, J. R. Cunningham et al., "Brainderived neurotrophic factor is released in the dorsal horn by distinctive patterns of afferent fiber stimulation," The Journal of Neuroscience, vol. 21, no. 12, pp. 4469-4477, 2001.

[47] M. Bergami, S. Santi, E. Formaggio et al., "Uptake and recycling of pro-BDNF for transmitter-induced secretion by cortical astrocytes," The Journal of Cell Biology, vol. 183, no. 2, pp. 213-221, 2008.

[48] R. Villanueva, "Neurobiology of major depressive disorder," Neural Plasticity, vol. 2013, Article ID 873278, 7 pages, 2013.

[49] R. Curtis, K. M. Adryan, J. L. Stark et al., "Differential role of the low affinity neurotrophin receptor (p75) in retrograde axonal transport of the neurotrophins," Neuron, vol. 14, no. 6, pp. 1201-1211, 1995.

[50] M. Zagrebelsky, A. Holz, G. Dechant, Y. A. Barde, T. Bonhoeffer, and M. Korte, "The p75 neurotrophin receptor negatively modulates dendrite complexity and spine density in hippocampal neurons," The Journal of Neuroscience, vol. 25, no. 43, pp. 9989-9999, 2005.

[51] N. H. Woo, H. K. Teng, C. J. Siao et al., "Activation of p75NTR by proBDNF facilitates hippocampal long-term depression," Nature Neuroscience, vol. 8, no. 8, pp. 10691077, 2005.

[52] H. K. Teng, K. K. Teng, R. Lee et al., "ProBDNF induces neuronal apoptosis via activation of a receptor complex of p75NTR and sortilin," The Journal of Neuroscience, vol. 25, no. 22 , pp. 5455-5463, 2005.

[53] K. Deinhardt, T. Kim, D. S. Spellman et al., "Neuronal growth cone retraction relies on proneurotrophin receptor signaling through Rac," Science Signaling, vol. 4, no. 202, article ra82, 2011.

[54] E. Messaoudi, S. W. Ying, T. Kanhema, S. D. Croll, and C. R. Bramham, "Brain-derived neurotrophic factor triggers transcription-dependent, late phase long-term potentiation in vivo," The Journal of Neuroscience, vol. 22, no. 17, pp. 7453-7461, 2002.

[55] Y. Lu, K. Christian, and B. Lu, "BDNF: a key regulator for protein synthesis-dependent LTP and long-term memory?" Neurobiology of Learning and Memory, vol. 89, no. 3, pp. 312-323, 2008.

[56] H. Kang and E. M. Schuman, "A requirement for local protein synthesis in neurotrophin-induced hippocampal synaptic plasticity," Science, vol. 273, no. 5280, pp. 1402-1406, 1996.

[57] R. Lee, P. Kermani, K. K. Teng, and B. L. Hempstead, "Regulation of cell survival by secreted proneurotrophins," Science, vol. 294, no. 5548, pp. 1945-1948, 2001.

[58] B. Lu, P. T. Pang, and N. H. Woo, "The yin and yang of neurotrophin action," Nature Reviews Neuroscience, vol. 6, no. 8, pp. 603-614, 2005.

[59] B. H. Lee and Y. K. Kim, "The roles of BDNF in the pathophysiology of major depression and in antidepressant treatment," Psychiatry Investigation, vol. 7, no. 4, pp. 231$235,2010$.

[60] B. H. Lee, H. Kim, S. H. Park, and Y. K. Kim, "Decreased plasma BDNF level in depressive patients," Journal of Affective Disorders, vol. 101, no. 1-3, pp. 239-244, 2007.

[61] T. Yoshida, M. Ishikawa, T. Niitsu et al., "Decreased serum levels of mature brain-derived neurotrophic factor (BDNF), but not its precursor proBDNF, in patients with major depressive disorder," PLoS One, vol. 7, no. 8, article e42676, 2012. 
[62] Y. K. Kim, H. P. Lee, S. D. Won et al., "Low plasma BDNF is associated with suicidal behavior in major depression," Progress in Neuro-Psychopharmacology \& Biological Psychiatry, vol. 31, no. 1, pp. 78-85, 2007.

[63] T. K. Birkenhager, S. Geldermans, W. W. Van den Broek, N. van Beveren, and D. Fekkes, "Serum brain-derived neurotrophic factor level in relation to illness severity and episode duration in patients with major depression," Journal of Psychiatric Research, vol. 46, no. 3, pp. 285-289, 2012.

[64] R. S. Duman, "Neuronal damage and protection in the pathophysiology and treatment of psychiatric illness: stress and depression," Dialogues in Clinical Neuroscience, vol. 11, no. 3, pp. 239-255, 2009.

[65] M. L. Molendijk, P. Spinhoven, M. Polak, B. A. Bus, B. W. Penninx, and B. M. Elzinga, "Serum BDNF concentrations as peripheral manifestations of depression: evidence from a systematic review and meta-analyses on 179 associations (N=9484)," Molecular Psychiatry, vol. 19, no. 7, pp. 791800, 2014.

[66] F. Matrisciano, S. Bonaccorso, A. Ricciardi et al., "Changes in BDNF serum levels in patients with major depression disorder (MDD) after 6 months treatment with sertraline, escitalopram, or venlafaxine," Journal of Psychiatric Research, vol. 43, no. 3, pp. 247-254, 2009.

[67] A. R. Brunoni, C. Baeken, R. Machado-Vieira, W. F. Gattaz, and M. A. Vanderhasselt, "BDNF blood levels after electroconvulsive therapy in patients with mood disorders: a systematic review and meta-analysis," The World Journal of Biological Psychiatry, vol. 15, no. 5, pp. 411-418, 2014.

[68] C. Engesser-Cesar, A. J. Anderson, and C. W. Cotman, "Wheel running and fluoxetine antidepressant treatment have differential effects in the hippocampus and the spinal cord," Neuroscience, vol. 144, no. 3, pp. 1033-1044, 2007.

[69] D. C. Steffens, C. E. Byrum, D. R. McQuoid et al., "Hippocampal volume in geriatric depression," Biological Psychiatry, vol. 48, no. 4, pp. 301-309, 2000.

[70] J. S. Dunham, J. F. Deakin, F. Miyajima, A. Payton, and C. T. Toro, "Expression of hippocampal brain-derived neurotrophic factor and its receptors in Stanley consortium brains," Journal of Psychiatric Research, vol. 43, no. 14, pp. 11751184, 2009.

[71] Y. Dwivedi, H. S. Rizavi, H. Zhang et al., "Neurotrophin receptor activation and expression in human postmortem brain: effect of suicide," Biological Psychiatry, vol. 65, no. 4, pp. 319-328, 2009.

[72] M. Thompson Ray, C.S. Weickert, E. Wyatt, and M. J. Webster, "Decreased BDNF, trkB-TK+ and GAD67 mRNA expression in the hippocampus of individuals with schizophrenia and mood disorders," Journal of Psychiatry \& Neuroscience, vol. 36, no. 3, pp. 195-203, 2011.

[73] Y. Dwivedi, H. S. Rizavi, R. R. Conley, R. C. Roberts, C. A. Tamminga, and G. N. Pandey, "Altered gene expression of brain-derived neurotrophic factor and receptor tyrosine kinase B in postmortem brain of suicide subjects," Archives of General Psychiatry, vol. 60, no. 8, pp. 804-815, 2003.

[74] Y. Dwivedi, H. S. Rizavi, H. Zhang, R. C. Roberts, R. R. Conley, and G. N. Pandey, "Aberrant extracellular signal-regulated kinase (ERK) $1 / 2$ signalling in suicide brain: role of ERK kinase 1 (MEK1)," The International Journal of Neuropsychopharmacology, vol. 12, no. 10, pp. 1337-1354, 2009.

[75] Y. Dwivedi, H. S. Rizavi, R. R. Conley, and G. N. Pandey, "ERK MAP kinase signaling in post-mortem brain of suicide subjects: differential regulation of upstream Raf kinases Raf-1 and B-Raf," Molecular Psychiatry, vol. 11, no. 1, pp. 86-98, 2006.

[76] D. Dowlatshahi, G. M. MacQueen, J. F. Wang, and L. T. Young, "Increased temporal cortex CREB concentrations and antidepressant treatment in major depression," Lancet, vol. 352, no. 9142, pp. 1754-1755, 1998.

[77] F. Duclot and M. Kabbaj, "Epigenetic mechanisms underlying the role of brain-derived neurotrophic factor in depression and response to antidepressants," The Journal of Experimental Biology, vol. 218, Part 1, pp. 21-31, 2015.

[78] A. Deveci, O. Aydemir, O. Taskin, F. Taneli, and A. Esen-Danaci, "Serum BDNF levels in suicide attempters related to psychosocial stressors: a comparative study with depression," Neuropsychobiology, vol. 56, no. 2-3, pp. 93-97, 2007.

[79] M. Verhagen, A. van der Meij, P. A. van Deurzen et al., "Meta-analysis of the BDNF Val66Met polymorphism in major depressive disorder: effects of gender and ethnicity," Molecular Psychiatry, vol. 15, no. 3, pp. 260-271, 2010.

[80] R. M. Legge, S. Sendi, J. H. Cole et al., "Modulatory effects of brain-derived neurotrophic factor Val66Met polymorphism on prefrontal regions in major depressive disorder," The British Journal of Psychiatry, vol. 206, no. 5, pp. 379-384, 2015.

[81] E. Shimizu, K. Hashimoto, and M. Iyo, "Ethnic difference of the BDNF 196G/A (val66met) polymorphism frequencies: the possibility to explain ethnic mental traits," American Journal of Medical Genetics. Part B, Neuropsychiatric Genetics, vol. 126B, no. 1, pp. 122-123, 2004.

[82] Z. Y. Chen, P. D. Patel, G. Sant et al., "Variant brain-derived neurotrophic factor (BDNF) (Met66) alters the intracellular trafficking and activity-dependent secretion of wild-type BDNF in neurosecretory cells and cortical neurons," The Journal of Neuroscience, vol. 24, no. 18, pp. 4401-4411, 2004.

[83] M. F. Egan, M. Kojima, J. H. Callicott et al., "The BDNF val66met polymorphism affects activity-dependent secretion of BDNF and human memory and hippocampal function," Cell, vol. 112, no. 2, pp. 257-269, 2003.

[84] J. A. Bueller, M. Aftab, S. Sen, D. Gomez-Hassan, M. Burmeister, and J. K. Zubieta, "BDNF Val66Met allele is associated with reduced hippocampal volume in healthy subjects," Biological Psychiatry, vol. 59, no. 9, pp. 812-815, 2006.

[85] P. R. Szeszko, R. Lipsky, C. Mentschel et al., "Brain-derived neurotrophic factor val66met polymorphism and volume of the hippocampal formation," Molecular Psychiatry, vol. 10, no. 7, pp. 631-636, 2005.

[86] L. Pezawas, B. A. Verchinski, V. S. Mattay et al., "The brainderived neurotrophic factor val66met polymorphism and variation in human cortical morphology," The Journal of Neuroscience, vol. 24, no. 45, pp. 10099-10102, 2004.

[87] N. Cardoner, V. Soria, M. Gratacòs et al., "Val66Met BDNF genotypes in melancholic depression: effects on brain structure and treatment outcome," Depression and Anxiety, vol. 30, no. 3, pp. 225-233, 2013.

[88] G. M. Hosang, C. Shiles, K. E. Tansey, P. McGuffin, and R. Uher, "Interaction between stress and the BDNF Val66Met polymorphism in depression: a systematic review and metaanalysis," BMC Medicine, vol. 12, p. 7, 2014.

[89] L. Gerritsen, I. Tendolkar, B. Franke et al., "BDNF Val66Met genotype modulates the effect of childhood adversity on 
subgenual anterior cingulate cortex volume in healthy subjects," Molecular Psychiatry, vol. 17, no. 6, pp. 597-603, 2012.

[90] J. M. Gatt, C. B. Nemeroff, C. Dobson-Stone et al., "Interactions between BDNF Val66Met polymorphism and early life stress predict brain and arousal pathways to syndromal depression and anxiety," Molecular Psychiatry, vol. 14, no. 7, pp. 681-695, 2009.

[91] Y. Pei, A. K. Smith, Y. Wang et al., "The brain-derived neurotrophic-factor (BDNF) val66met polymorphism is associated with geriatric depression: a meta-analysis," American Journal of Medical Genetics. Part B, Neuropsychiatric Genetics, vol. 159B, no. 5, pp. 560-566, 2012.

[92] T. Yan, L. Wang, W. Kuang et al., "Brain-derived neurotrophic factor Val66Met polymorphism association with antidepressant efficacy: a systematic review and meta-analysis," Asia Pacific Psychiatry, vol. 6, no. 3, pp. 241-251, 2014.

[93] A. R. Hariri, T. E. Goldberg, V. S. Mattay et al., "Brainderived neurotrophic factor val66met polymorphism affects human memory-related hippocampal activity and predicts memory performance," The Journal of Neuroscience, vol. 23, no. 17, pp. 6690-6694, 2003.

[94] Z. J. Huang, A. Kirkwood, T. Pizzorusso et al., "BDNF regulates the maturation of inhibition and the critical period of plasticity in mouse visual cortex," Cell, vol. 98, no. 6, pp. 739-755, 1999.

[95] A. Figurov, L. D. Pozzo-Miller, P. Olafsson, T. Wang, and B. $\mathrm{Lu}$, "Regulation of synaptic responses to high-frequency stimulation and LTP by neurotrophins in the hippocampus," Nature, vol. 381, no. 6584, pp. 706-709, 1996.

[96] Z. C. Baquet, J. A. Gorski, and K. R. Jones, "Early striatal dendrite deficits followed by neuron loss with advanced age in the absence of anterograde cortical brain-derived neurotrophic factor," The Journal of Neuroscience, vol. 24, no. 17, pp. 4250-4258, 2004.

[97] J. A. Gorski, S. R. Zeiler, S. Tamowski, and K. R. Jones, "Brain-derived neurotrophic factor is required for the maintenance of cortical dendrites," The Journal of Neuroscience, vol. 23, no. 17, pp. 6856-6865, 2003.

[98] L. M. Grover and T. J. Teyler, "Two components of long-term potentiation induced by different patterns of afferent activation," Nature, vol. 347, no. 6292, pp. 477-479, 1990.

[99] G. L. Collingridge and T. V. Bliss, "Memories of NMDA receptors and LTP," Trends in Neurosciences, vol. 18, no. 2, pp. 54-56, 1995.

[100] U. V. Nagerl, N. Eberhorn, S. B. Cambridge, and T. Bonhoeffer, "Bidirectional activity-dependent morphological plasticity in hippocampal neurons," Neuron, vol. 44, no. 5, pp. 759-767, 2004.

[101] C. Heise, F. Gardoni, L. Culotta, M. di Luca, C. Verpelli, and C. Sala, "Elongation factor-2 phosphorylation in dendrites and the regulation of dendritic mRNA translation in neurons," Frontiers in Cellular Neuroscience, vol. 8, p. 35, 2014.

[102] T. Dawood, J. Anderson, D. Barton et al., "Reduced overflow of BDNF from the brain is linked with suicide risk in depressive illness," Molecular Psychiatry, vol. 12, no. 11, pp. 981983, 2007.

[103] G. Zhao, C. Zhang, J. Chen et al., "Ratio of mBDNF to proBDNF for differential diagnosis of major depressive disorder and bipolar depression," Molecular Neurobiology, vol. 54, no. 7, 2016.
[104] M. Polyakova, K. Stuke, K. Schuemberg, K. Mueller, P. Schoenknecht, and M. L. Schroeter, "BDNF as a biomarker for successful treatment of mood disorders: a systematic \& quantitative meta-analysis," Journal of Affective Disorders, vol. 174, pp. 432-440, 2015.

[105] R. H. Lipsky and A. M. Marini, "Brain-derived neurotrophic factor in neuronal survival and behavior-related plasticity," Annals of the New York Academy of Sciences, vol. 1122, pp. 130-143, 2007.

[106] G. Laje, N. Lally, D. Mathews et al., "Brain-derived neurotrophic factor Val66Met polymorphism and antidepressant efficacy of ketamine in depressed patients," Biological Psychiatry, vol. 72, no. 11, pp. e27-e28, 2012.

[107] F. Holsboer, "The corticosteroid receptor hypothesis of depression," Neuropsychopharmacology, vol. 23, no. 5, pp. 477-501, 2000.

[108] P. Willner and C. Belzung, "Treatment-resistant depression: are animal models of depression fit for purpose?" Psychopharmacology, vol. 232, no. 19, pp. 3473-3495, 2015.

[109] B. Czeh, E. Fuchs, O. Wiborg, and M. Simon, "Animal models of major depression and their clinical implications," Progress in Neuro-Psychopharmacology \& Biological Psychiatry, vol. 64, pp. 293-310, 2016.

[110] J. Harro, "Animal models of depression vulnerability," Current Topics in Behavioral Neurosciences, vol. 14, pp. 29-54, 2013.

[111] D. H. Overstreet, "Modeling depression in animal models," Methods in Molecular Biology, vol. 829, pp. 125-144, 2012.

[112] H. M. Abelaira, G. Z. Reus, and J. Quevedo, "Animal models as tools to study the pathophysiology of depression," Revista Brasileira de Psiquiatria, vol. 35, Supplement 2, pp. S112S120, 2013.

[113] O. F. O'Leary and J. F. Cryan, “Towards translational rodent models of depression," Cell and Tissue Research, vol. 354, no. 1, pp. 141-153, 2013.

[114] A. R. Patten, S. Y. Yau, C. J. Fontaine, A. Meconi, R. C. Wortman, and B. R. Christie, "The benefits of exercise on structural and functional plasticity in the rodent hippocampus of different disease models," Brain Plasticity, vol. 1, no. 1, pp. 97-127, 2015.

[115] R. Zhang, Z. Peng, H. Wang et al., "Gastrodin ameliorates depressive-like behaviors and up-regulates the expression of BDNF in the hippocampus and hippocampal-derived astrocyte of rats," Neurochemical Research, vol. 39, no. 1, pp. 172-179, 2014.

[116] A. Russo-Neustadt, T. Ha, R. Ramirez, and J. P. Kesslak, "Physical activity-antidepressant treatment combination: impact on brain-derived neurotrophic factor and behavior in an animal model," Behavioural Brain Research, vol. 120, no. 1, pp. 87-95, 2001.

[117] B. A. Hoshaw, J. E. Malberg, and I. Lucki, "Central administration of IGF-I and BDNF leads to long-lasting antidepressantlike effects," Brain Research, vol. 1037, no. 1-2, pp. 204-208, 2005.

[118] J. A. Siuciak, D. R. Lewis, S. J. Wiegand, and R. M. Lindsay, "Antidepressant-like effect of brain-derived neurotrophic factor (BDNF)," Pharmacology, Biochemistry, and Behavior, vol. 56, no. 1, pp. 131-137, 1997.

[119] A. L. Coppell, Q. Pei, and T. S. Zetterstrom, "Bi-phasic change in BDNF gene expression following antidepressant 
drug treatment," Neuropharmacology, vol. 44, no. 7, pp. 903910, 2003.

[120] F. Calabrese, R. Molteni, C. Gabriel, E. Mocaer, G. Racagni, and M. A. Riva, "Modulation of neuroplastic molecules in selected brain regions after chronic administration of the novel antidepressant agomelatine," Psychopharmacology, vol. 215, no. 2, pp. 267-275, 2011.

[121] R. S. Duman, G. R. Heninger, and E. J. Nestler, “A molecular and cellular theory of depression," Archives of General Psychiatry, vol. 54, no. 7, pp. 597-606, 1997.

[122] L. M. Monteggia, B. Luikart, M. Barrot et al., "Brain-derived neurotrophic factor conditional knockouts show gender differences in depression-related behaviors," Biological Psychiatry, vol. 61, no. 2, pp. 187-197, 2007.

[123] H. D. Schmidt and R. S. Duman, "Peripheral BDNF produces antidepressant-like effects in cellular and behavioral models," Neuropsychopharmacology, vol. 35, no. 12, pp. 2378-2391, 2010.

[124] E. Koponen, T. Rantamaki, V. Voikar, T. Saarelainen, E. MacDonald, and E. Castren, "Enhanced BDNF signaling is associated with an antidepressant-like behavioral response and changes in brain monoamines," Cellular and Molecular Neurobiology, vol. 25, no. 6, pp. 973-980, 2005.

[125] A. Govindarajan, B. S. Rao, D. Nair et al., "Transgenic brainderived neurotrophic factor expression causes both anxiogenic and antidepressant effects," Proceedings of the National Academy of Sciences of the United States of America, vol. 103, no. 35, pp. 13208-13213, 2006.

[126] K. H. Choy, Y. de Visser, N. R. Nichols, and M. van den Buuse, "Combined neonatal stress and young-adult glucocorticoid stimulation in rats reduce BDNF expression in hippocampus: effects on learning and memory," Hippocampus, vol. 18, no. 7, pp. 655-667, 2008.

[127] F. Nottebohm, "Why are some neurons replaced in adult brain?" The Journal of Neuroscience, vol. 22, no. 3, pp. 624628, 2002.

[128] M. Sairanen, G. Lucas, P. Ernfors, M. Castren, and E. Castren, "Brain-derived neurotrophic factor and antidepressant drugs have different but coordinated effects on neuronal turnover, proliferation, and survival in the adult dentate gyrus," The Journal of Neuroscience, vol. 25, no. 5, pp. 1089-1094, 2005.

[129] C. Phillips, M. A. Baktir, D. Das, B. Lin, and A. Salehi, "The link between physical activity and cognitive dysfunction in Alzheimer disease," Physical Therapy, vol. 95, no. 7, pp. 1046-1060, 2015.

[130] C. Phillips, M. A. Baktir, M. Srivatsan, and A. Salehi, "Neuroprotective effects of physical activity on the brain: a closer look at trophic factor signaling," Frontiers in Cellular Neuroscience, vol. 8, p. 170, 2014.

[131] K. M. Christian, H. Song, and G. L. Ming, "Functions and dysfunctions of adult hippocampal neurogenesis," Annual Review of Neuroscience, vol. 37, pp. 243-262, 2014.

[132] C. Schmidt-Hieber, P. Jonas, and J. Bischofberger, "Enhanced synaptic plasticity in newly generated granule cells of the adult hippocampus," Nature, vol. 429, no. 6988, pp. 184187, 2004.

[133] T. F. Yuan, F. Paes, O. Arias-Carrion, N. B. Ferreira Rocha, A. S. de Sa Filho, and S. Machado, "Neural mechanisms of exercise: anti-depression, neurogenesis, and serotonin signaling," CNS \& Neurological Disorders Drug Targets, vol. 14, no. 10, pp. 1307-1311, 2015.
[134] A. Caviedes, C. Lafourcade, C. Soto, and U. Wyneken, "BDNF/NF-kB signaling in the neurobiology of depression," Current Pharmaceutical Design, 2017.

[135] M. Bergami, R. Rimondini, S. Santi, R. Blum, M. Gotz, and M. Canossa, "Deletion of TrkB in adult progenitors alters newborn neuron integration into hippocampal circuits and increases anxiety-like behavior," Proceedings of the National Academy of Sciences of the United States of America, vol. 105, no. 40, pp. 15570-15575, 2008.

[136] V. A. Redila and B. R. Christie, "Exercise-induced changes in dendritic structure and complexity in the adult hippocampal dentate gyrus," Neuroscience, vol. 137, no. 4, pp. 1299-1307, 2006.

[137] B. D. Eadie, V. A. Redila, and B. R. Christie, "Voluntary exercise alters the cytoarchitecture of the adult dentate gyrus by increasing cellular proliferation, dendritic complexity, and spine density," The Journal of Comparative Neurology, vol. 486, no. 1, pp. 39-47, 2005.

[138] A. M. Stranahan, D. Khalil, and E. Gould, "Running induces widespread structural alterations in the hippocampus and entorhinal cortex," Hippocampus, vol. 17, no. 11, pp. 10171022, 2007.

[139] M. Adachi, M. Barrot, A. E. Autry, D. Theobald, and L. M. Monteggia, "Selective loss of brain-derived neurotrophic factor in the dentate gyrus attenuates antidepressant efficacy," Biological Psychiatry, vol. 63, no. 7, pp. 642-649, 2008.

[140] A. J. Eisch, C. A. Bolaños, J. de Wit et al., "Brain-derived neurotrophic factor in the ventral midbrain-nucleus accumbens pathway: a role in depression," Biological Psychiatry, vol. 54, no. 10, pp. 994-1005, 2003.

[141] O. Berton, C. A. McClung, R. J. Dileone et al., "Essential role of BDNF in the mesolimbic dopamine pathway in social defeat stress," Science, vol. 311, no. 5762, pp. 864-868, 2006.

[142] O. Guillin, J. Diaz, P. Carroll, N. Griffon, J. C. Schwartz, and P. Sokoloff, "BDNF controls dopamine D3 receptor expression and triggers behavioural sensitization," Nature, vol. 411, no. 6833, pp. 86-89, 2001.

[143] J. W. Grimm, L. Lu, T. Hayashi, B. T. Hope, T. P. Su, and Y. Shaham, "Time-dependent increases in brain-derived neurotrophic factor protein levels within the mesolimbic dopamine system after withdrawal from cocaine: implications for incubation of cocaine craving," The Journal of Neuroscience, vol. 23, no. 3, pp. 742-747, 2003.

[144] J. Goggi, I. A. Pullar, S. L. Carney, and H. F. Bradford, "Signalling pathways involved in the short-term potentiation of dopamine release by BDNF," Brain Research, vol. 968, no. 1, pp. 156-161, 2003.

[145] J. W. Cordeira, L. Frank, M. Sena-Esteves, E. N. Pothos, and M. Rios, "Brain-derived neurotrophic factor regulates hedonic feeding by acting on the mesolimbic dopamine system," The Journal of Neuroscience, vol. 30, no. 7, pp. 2533-2541, 2010.

[146] F. Maekawa, K. Fujiwara, M. Toriya et al., "Brain-derived neurotrophic factor in VMH as the causal factor for and therapeutic tool to treat visceral adiposity and hyperleptinemia in type 2 diabetic Goto-Kakizaki rats," Front Synaptic Neuroscience, vol. 5, p. 7, 2013.

[147] P. Homan, S. Grob, G. Milos et al., "The role of BDNF, leptin, and catecholamines in reward learning in bulimia nervosa," The International Journal of Neuropsychopharmacology, vol. 18 , no. 5, 2014. 
[148] C. H. Duman, L. Schlesinger, M. Kodama, D. S. Russell, and R. S. Duman, "A role for MAP kinase signaling in behavioral models of depression and antidepressant treatment," Biological Psychiatry, vol. 61, no. 5, pp. 661-670, 2007.

[149] W. N. Marsden, "Synaptic plasticity in depression: molecular, cellular and functional correlates," Progress in NeuroPsychopharmacology \& Biological Psychiatry, vol. 43, pp. 168-184, 2013.

[150] B. Lu, G. Nagappan, and Y. Lu, "BDNF and synaptic plasticity, cognitive function, and dysfunction," Handbook of Experimental Pharmacology, vol. 220, pp. 223-250, 2014.

[151] H. Thoenen, "Neurotrophins and activity-dependent plasticity," Progress in Brain Research, vol. 128, pp. 183-191, 2000.

[152] T. M. Schneider, C. Beynon, A. Sartorius, A. W. Unterberg, and K. L. Kiening, "Deep brain stimulation of the lateral habenular complex in treatment-resistant depression: traps and pitfalls of trajectory choice," Neurosurgery, vol. 72, Supplement 2 Operative, pp. ons184-ons193, 2013, discussion ons193.

[153] M. D. Dobrossy, L. L. Furlanetti, and V. A. Coenen, "Electrical stimulation of the medial forebrain bundle in pre-clinical studies of psychiatric disorders," Neuroscience and Biobehavioral Reviews, vol. 49, pp. 32-42, 2015.

[154] M. T. Berlim, A. McGirr, F. Van den Eynde, M. P. Fleck, and P. Giacobbe, "Effectiveness and acceptability of deep brain stimulation (DBS) of the subgenual cingulate cortex for treatment-resistant depression: a systematic review and exploratory meta-analysis," Journal of Affective Disorders, vol. 159, pp. 31-38, 2014.

[155] A. Sartorius and F. A. Henn, "Deep brain stimulation of the lateral habenula in treatment resistant major depression," Medical Hypotheses, vol. 69, no. 6, pp. 1305-1308, 2007.

[156] G. J. Siegle, S. R. Steinhauer, M. E. Thase, V. A. Stenger, and C. S. Carter, "Can't shake that feeling: event-related fMRI assessment of sustained amygdala activity in response to emotional information in depressed individuals," Biological Psychiatry, vol. 51, no. 9, pp. 693-707, 2002.

[157] D. Cotter, D. Mackay, G. Chana, C. Beasley, S. Landau, and I. P. Everall, "Reduced neuronal size and glial cell density in area 9 of the dorsolateral prefrontal cortex in subjects with major depressive disorder," Cerebral Cortex, vol. 12, no. 4, pp. 386-394, 2002.

[158] D. Cotter, D. Mackay, S. Landau, R. Kerwin, and I. Everall, "Reduced glial cell density and neuronal size in the anterior cingulate cortex in major depressive disorder," Archives of General Psychiatry, vol. 58, no. 6, pp. 545-553, 2001.

[159] S. Campbell and G. MacQueen, "An update on regional brain volume differences associated with mood disorders," Current Opinion in Psychiatry, vol. 19, no. 1, pp. 25-33, 2006.

[160] G. Rajkowska, "Histopathology of the prefrontal cortex in major depression: what does it tell us about dysfunctional monoaminergic circuits?" Progress in Brain Research, vol. 126, pp. 397-412, 2000.

[161] S. Lui, Q. Wu, L. Qiu et al., "Resting-state functional connectivity in treatment-resistant depression," The American Journal of Psychiatry, vol. 168, no. 6, pp. 642-648, 2011.

[162] M. N. Quan, N. Zhang, Y. Y. Wang, T. Zhang, and Z. Yang, "Possible antidepressant effects and mechanisms of memantine in behaviors and synaptic plasticity of a depression rat model," Neuroscience, vol. 182, pp. 88-97, 2011.
[163] J. P. Hamilton and I. H. Gotlib, "Neural substrates of increased memory sensitivity for negative stimuli in major depression," Biological Psychiatry, vol. 63, no. 12, pp. 1155$1162,2008$.

[164] C. L. Fales, D. M. Barch, M. M. Rundle et al., “Altered emotional interference processing in affective and cognitivecontrol brain circuitry in major depression," Biological Psychiatry, vol. 63, no. 4, pp. 377-384, 2008.

[165] W. C. Drevets, J. L. Price, J. R. Simpson Jr et al., "Subgenual prefrontal cortex abnormalities in mood disorders," Nature, vol. 386, no. 6627, pp. 824-827, 1997.

[166] G. M. MacQueen, S. Campbell, B. S. McEwen et al., "Course of illness, hippocampal function, and hippocampal volume in major depression," Proceedings of the National Academy of Sciences of the United States of America, vol. 100, no. 3, pp. 1387-1392, 2003.

[167] Y. I. Sheline, D. M. Barch, J. M. Donnelly, J. M. Ollinger, A. Z. Snyder, and M. A. Mintun, "Increased amygdala response to masked emotional faces in depressed subjects resolves with antidepressant treatment: an fMRI study," Biological Psychiatry, vol. 50, no. 9, pp. 651-658, 2001.

[168] L. Mah, C. A. Zarate Jr, J. Singh et al., "Regional cerebral glucose metabolic abnormalities in bipolar II depression," Biological Psychiatry, vol. 61, no. 6, pp. 765-775, 2007.

[169] R. Norbury, S. Selvaraj, M. J. Taylor, C. Harmer, and P. J. Cowen, "Increased neural response to fear in patients recovered from depression: a $3 \mathrm{~T}$ functional magnetic resonance imaging study," Psychological Medicine, vol. 40, no. 3, pp. 425-432, 2010.

[170] A. Neumeister, A. C. Nugent, T. Waldeck et al., "Neural and behavioral responses to tryptophan depletion in unmedicated patients with remitted major depressive disorder and controls," Archives of General Psychiatry, vol. 61, no. 8, pp. 765-773, 2004.

[171] S. G. Disner, C. G. Beevers, E. A. Haigh, and A. T. Beck, "Neural mechanisms of the cognitive model of depression," Nature Reviews. Neuroscience, vol. 12, no. 8, pp. 467-477, 2011.

[172] W. C. Drevets, "Neuroimaging and neuropathological studies of depression: implications for the cognitive-emotional features of mood disorders," Current Opinion in Neurobiology, vol. 11, no. 2, pp. 240-249, 2001.

[173] C. Phillips, "Physical activity modulates common neuroplasticity substrates in depressive and bipolar disorder," Neural Plasticity, vol. 2017, Article ID 7014146, 37 pages, 2017.

[174] B. I. Goldstein and L. T. Young, "Toward clinically applicable biomarkers in bipolar disorder: focus on BDNF, inflammatory markers, and endothelial function," Current Psychiatry Reports, vol. 15, no. 12, p. 425, 2013.

[175] E. Castren, "Is mood chemistry?" Nature Reviews Neuroscience, vol. 6, no. 3, pp. 241-246, 2005.

[176] S. Campbell, M. Marriott, C. Nahmias, and G. M. MacQueen, "Lower hippocampal volume in patients suffering from depression: a meta-analysis," The American Journal of Psychiatry, vol. 161, no. 4, pp. 598-607, 2004.

[177] J. Savitz and W. C. Drevets, "Bipolar and major depressive disorder: neuroimaging the developmental-degenerative divide," Neuroscience and Biobehavioral Reviews, vol. 33, no. 5, pp. 699-771, 2009.

[178] B. Czeh and P. J. Lucassen, "What causes the hippocampal volume decrease in depression? Are neurogenesis, glial 
changes and apoptosis implicated?" European Archives of Psychiatry and Clinical Neuroscience, vol. 257, no. 5, pp. 250-260, 2007.

[179] M. R. Bennett, "The prefrontal-limbic network in depression: a core pathology of synapse regression," Progress in Neurobiology, vol. 93, no. 4, pp. 457-467, 2011.

[180] T. V. Bliss and G. L. Collingridge, "A synaptic model of memory: long-term potentiation in the hippocampus," Nature, vol. 361, no. 6407, pp. 31-39, 1993.

[181] G. Nagappan, E. Zaitsev, V. V. Senatorov Jr., J. Yang, B. L. Hempstead, and B. Lu, "Control of extracellular cleavage of proBDNF by high frequency neuronal activity," Proceedings of the National Academy of Sciences of the United States of America, vol. 106, no. 4, pp. 1267-1272, 2009.

[182] M. F. Bear and W. C. Abraham, "Long-term depression in hippocampus," Annual Review of Neuroscience, vol. 19, pp. 437-462, 1996.

[183] G. G. Turrigiano, K. R. Leslie, N. S. Desai, L. C. Rutherford, and S. B. Nelson, "Activity-dependent scaling of quantal amplitude in neocortical neurons," Nature, vol. 391, no. 6670, pp. 892-896, 1998.

[184] A. Simonetti, G. Sani, C. Dacquino et al., "Hippocampal subfield volumes in short- and long-term lithium-treated patients with bipolar I disorder," Bipolar Disorders, vol. 18, no. 4, pp. 352-362, 2016.

[185] N. V. Malykhin, R. Carter, P. Seres, and N. J. Coupland, "Structural changes in the hippocampus in major depressive disorder: contributions of disease and treatment," Journal of Psychiatry \& Neuroscience, vol. 35, no. 5, pp. 337-343, 2010.

[186] M. Otten and M. Meeter, "Hippocampal structure and function in individuals with bipolar disorder: a systematic review," Journal of Affective Disorders, vol. 174, pp. 113125, 2015.

[187] T. Frodl, M. Jäger, I. Smajstrlova et al., "Effect of hippocampal and amygdala volumes on clinical outcomes in major depression: a 3-year prospective magnetic resonance imaging study," Journal of Psychiatry \& Neuroscience, vol. 33, no. 5, pp. 423-430, 2008.

[188] O. F. O'Leary, X. Wu, and E. Castren, "Chronic fluoxetine treatment increases expression of synaptic proteins in the hippocampus of the ovariectomized rat: role of BDNF signalling," Psychoneuroendocrinology, vol. 34, no. 3, pp. 367-381, 2009.

[189] T. Hajszan, K. Szigeti-Buck, N. L. Sallam et al., "Effects of estradiol on learned helplessness and associated remodeling of hippocampal spine synapses in female rats," Biological Psychiatry, vol. 67, no. 2, pp. 168-174, 2010.

[190] F. Chen, T. M. Madsen, G. Wegener, and J. R. Nyengaard, "Repeated electroconvulsive seizures increase the total number of synapses in adult male rat hippocampus," European Neuropsychopharmacology, vol. 19, no. 5, pp. 329-338, 2009.

[191] M. Sairanen, O. F. O'Leary, J. E. Knuuttila, and E. Castren, "Chronic antidepressant treatment selectively increases expression of plasticity-related proteins in the hippocampus and medial prefrontal cortex of the rat," Neuroscience, vol. 144, no. 1, pp. 368-374, 2007.

[192] R. D. Airan, L. A. Meltzer, M. Roy, Y. Gong, H. Chen, and K. Deisseroth, "High-speed imaging reveals neurophysiological links to behavior in an animal model of depression," Science, vol. 317, no. 5839, pp. 819-823, 2007.
[193] T. Rantamäki, P. Hendolin, A. Kankaanpää et al., "Pharmacologically diverse antidepressants rapidly activate brainderived neurotrophic factor receptor TrkB and induce phospholipase-Cgamma signaling pathways in mouse brain," Neuropsychopharmacology, vol. 32, no. 10, pp. 2152-2162, 2007.

[194] T. Saarelainen, P. Hendolin, G. Lucas et al., "Activation of the TrkB neurotrophin receptor is induced by antidepressant drugs and is required for antidepressant-induced behavioral effects," The Journal of Neuroscience, vol. 23, no. 1, pp. 349357, 2003.

[195] U. Wyneken, M. Sandoval, S. Sandoval et al., "Clinically relevant doses of fluoxetine and reboxetine induce changes in the TrkB content of central excitatory synapses," Neuropsychopharmacology, vol. 31, no. 11, pp. 2415-2423, 2006.

[196] J. F. Maya Vetencourt, A. Sale, A. Viegi et al., "The antidepressant fluoxetine restores plasticity in the adult visual cortex," Science, vol. 320, no. 5874, pp. 385-388, 2008.

[197] E. Castren and T. Rantamaki, "The role of BDNF and its receptors in depression and antidepressant drug action: reactivation of developmental plasticity," Developmental Neurobiology, vol. 70, no. 5, pp. 289-297, 2010.

[198] K. Kobayashi, Y. Ikeda, A. Sakai et al., "Reversal of hippocampal neuronal maturation by serotonergic antidepressants," Proceedings of the National Academy of Sciences of the United States of America, vol. 107, no. 18, pp. 84348439, 2010.

[199] N. N. Karpova, A. Pickenhagen, J. Lindholm et al., "Fear erasure in mice requires synergy between antidepressant drugs and extinction training," Science, vol. 334, no. 6063, pp. 1731-1734, 2011.

[200] F. Chollet, J. Tardy, J. F. Albucher et al., "Fluoxetine for motor recovery after acute ischaemic stroke (FLAME): a randomised placebo-controlled trial," Lancet Neurology, vol. 10, no. 2, pp. 123-130, 2011.

[201] E. Castren and R. Hen, "Neuronal plasticity and antidepressant actions," Trends in Neurosciences, vol. 36, no. 5, pp. 259-267, 2013.

[202] Y. L. Tan, D. F. Zhou, L. Y. Cao, Y. Z. Zou, and X. Y. Zhang, "Decreased BDNF in serum of patients with chronic schizophrenia on long-term treatment with antipsychotics," Neuroscience Letters, vol. 382, no. 1-2, pp. 27-32, 2005.

[203] C. Phillips, A. Fahimi, D. Das, F. S. Mojabi, R. Ponnusamy, and A. Salehi, "Noradrenergic system in Down syndrome and Alzheimer's disease a target for therapy," Current Alzheimer Research, vol. 13, no. 1, pp. 68-83, 2016.

[204] L. Bherer, K. I. Erickson, and T. Liu-Ambrose, "Physical exercise and brain functions in older adults," Journal Aging Research, vol. 2013, article 197326, 2 pages, 2013.

[205] R. W. Motl, A. S. Birnbaum, M. Y. Kubik, and R. K. Dishman, "Naturally occurring changes in physical activity are inversely related to depressive symptoms during early adolescence," Psychosomatic Medicine, vol. 66, no. 3, pp. 336-342, 2004.

[206] K. Abu-Omar, A. Rutten, and V. Lehtinen, "Mental health and physical activity in the European Union," Sozial- und Präventivmedizin, vol. 49, no. 5, pp. 301-309, 2004.

[207] R. Pemberton and M. D. Fuller Tyszkiewicz, "Factors contributing to depressive mood states in everyday life: a systematic review," Journal of Affective Disorders, vol. 200, pp. 103-110, 2016. 
[208] F. B. Schuch, D. Vancampfort, J. Richards, S. Rosenbaum, P. B. Ward, and B. Stubbs, "Exercise as a treatment for depression: a meta-analysis adjusting for publication bias," Journal of Psychiatric Research, vol. 77, pp. 42-51, 2016.

[209] S. Kvam, C. L. Kleppe, I. H. Nordhus, and A. Hovland, "Exercise as a treatment for depression: a meta-analysis," Journal of Affective Disorders, vol. 202, pp. 67-86, 2016.

[210] B. M. Hoffman, M. A. Babyak, W. E. Craighead et al., "Exercise and pharmacotherapy in patients with major depression: one-year follow-up of the SMILE study," Psychosomatic Medicine, vol. 73, no. 2, pp. 127-133, 2011.

[211] M. Babyak, J. A. Blumenthal, S. Herman et al., "Exercise treatment for major depression: maintenance of therapeutic benefit at 10 months," Psychosomatic Medicine, vol. 62, no. 5, pp. 633-638, 2000.

[212] G. Christofoletti, M. M. Oliani, L. T. Bucken-Gobbi, S. Gobbi, F. Beinotti, and F. Stella, "Physical activity attenuates neuropsychiatric disturbances and caregiver burden in patients with dementia," Clinics (São Paulo, Brazil), vol. 66, no. 4, pp. 613-618, 2011.

[213] N. C. Berchtold, G. Chinn, M. Chou, J. P. Kesslak, and C. W. Cotman, "Exercise primes a molecular memory for brainderived neurotrophic factor protein induction in the rat hippocampus," Neuroscience, vol. 133, no. 3, pp. 853-861, 2005.

[214] E. Y. Yuen, J. Wei, W. Liu, P. Zhong, X. Li, and Z. Yan, "Repeated stress causes cognitive impairment by suppressing glutamate receptor expression and function in prefrontal cortex," Neuron, vol. 73, no. 5, pp. 962-977, 2012.

[215] S. M. Gibney, B. McGuinness, C. Prendergast, A. Harkin, and T. J. Connor, "Poly I:C-induced activation of the immune response is accompanied by depression and anxiety-like behaviours, kynurenine pathway activation and reduced BDNF expression," Brain, Behavior, and Immunity, vol. 28, pp. 170-181, 2013.

[216] R. Yoshimura, H. Hori, A. Katsuki, K. Atake, and J. Nakamura, "Serum levels of brain-derived neurotrophic factor (BDNF), proBDNF and plasma 3-methoxy-4-hydroxyphenylglycol levels in chronic schizophrenia," Annals of General Psychiatry, vol. 15, p. 1, 2016.

[217] S. M. Rothman and M. P. Mattson, "Activity-dependent, stress-responsive BDNF signaling and the quest for optimal brain health and resilience throughout the lifespan," Neuroscience, vol. 239, pp. 228-240, 2013.

[218] E. Lee and H. Son, "Adult hippocampal neurogenesis and related neurotrophic factors,” BMB Reports, vol. 42, no. 5, pp. 239-244, 2009.

[219] D. P. Devanand, G. Pradhaban, X. Liu et al., "Hippocampal and entorhinal atrophy in mild cognitive impairment: prediction of Alzheimer disease," Neurology, vol. 68, no. 11, pp. 828-836, 2007.

[220] L. G. Apostolova, R. A. Dutton, I. D. Dinov et al., "Conversion of mild cognitive impairment to Alzheimer disease predicted by hippocampal atrophy maps," Archives of Neurology, vol. 63, no. 5, pp. 693-699, 2006.

[221] C. Nabkasorn, N. Miyai, A. Sootmongkol et al., "Effects of physical exercise on depression, neuroendocrine stress hormones and physiological fitness in adolescent females with depressive symptoms," European Journal of Public Health, vol. 16, no. 2, pp. 179-184, 2006.

[222] C. S. Woolley, E. Gould, and B. S. McEwen, "Exposure to excess glucocorticoids alters dendritic morphology of adult hippocampal pyramidal neurons," Brain Research, vol. 531, no. 1-2, pp. 225-231, 1990.

[223] W. Cui, N. D. Allen, M. Skynner, B. Gusterson, and A. J. Clark, "Inducible ablation of astrocytes shows that these cells are required for neuronal survival in the adult brain," Glia, vol. 34, no. 4, pp. 272-282, 2001.

[224] D. G. Diniz, C. A. Foro, C. M. Rego et al., "Environmental impoverishment and aging alter object recognition, spatial learning, and dentate gyrus astrocytes," The European Journal of Neuroscience, vol. 32, no. 3, pp. 509-519, 2010.

[225] Y. Ye, G. Wang, H. Wang, and X. Wang, "Brain-derived neurotrophic factor (BDNF) infusion restored astrocytic plasticity in the hippocampus of a rat model of depression," Neuroscience Letters, vol. 503, no. 1, pp. 15-19, 2011.

[226] A. Fahimi, M. A. Baktir, S. Moghadam et al., "Physical exercise induces structural alterations in the hippocampal astrocytes: exploring the role of BDNF-TrkB signaling," Brain Structure \& Function, vol. 222, no. 4, pp. 1797-1808, 2017.

[227] M. A. Alomari, O. F. Khabour, K. H. Alzoubi, and M. A. Alzubi, "Combining restricted diet with forced or voluntary exercises improves hippocampal BDNF and cognitive function in rats," The International Journal of Neuroscience, vol. 126, no. 4, pp. 366-373, 2016.

[228] B. Lu, "Pro-region of neurotrophins: role in synaptic modulation," Neuron, vol. 39, no. 5, pp. 735-738, 2003.

[229] J. A. Blumenthal, M. A. Babyak, P. M. Doraiswamy et al., "Exercise and pharmacotherapy in the treatment of major depressive disorder," Psychosomatic Medicine, vol. 69, no. 7, pp. 587-596, 2007.

[230] F. Gomez-Pinilla, Z. Ying, R. R. Roy, R. Molteni, and V. R. Edgerton, "Voluntary exercise induces a BDNF-mediated mechanism that promotes neuroplasticity," Journal of Neurophysiology, vol. 88, no. 5, pp. 2187-2195, 2002.

[231] R. M. Post, "Role of BDNF in bipolar and unipolar disorder: clinical and theoretical implications," Journal of Psychiatric Research, vol. 41, no. 12, pp. 979-990, 2007.

[232] J. Mata, R. J. Thompson, and I. H. Gotlib, "BDNF genotype moderates the relation between physical activity and depressive symptoms," Health Psychology, vol. 29, no. 2, pp. 130133, 2010.

[233] J. A. Zoladz, A. Pilc, J. Majerczak, M. Grandys, J. ZapartBukowska, and K. Duda, "Endurance training increases plasma brain-derived neurotrophic factor concentration in young healthy men," Journal of Physiology and Pharmacology, vol. 59, Supplement 7, pp. 119-132, 2008.

[234] T. Seifert, P. Brassard, M. Wissenberg et al., "Endurance training enhances BDNF release from the human brain," American Journal of Physiology. Regulatory, Integrative and Comparative Physiology, vol. 298, no. 2, pp. R372-R377, 2010.

[235] R. Ruscheweyh, C. Willemer, K. Krüger et al., "Physical activity and memory functions: an interventional study," Neurobiology of Aging, vol. 32, no. 7, pp. 1304-1319, 2011.

[236] E. W. Griffin, S. Mullally, C. Foley, S. A. Warmington, S. M. O'Mara, and A. M. Kelly, "Aerobic exercise improves hippocampal function and increases BDNF in the serum of young adult males," Physiology \& Behavior, vol. 104, no. 5, pp. 934-941, 2011.

[237] A. C. Pereira, D. E. Huddleston, A. M. Brickman et al., "An in vivo correlate of exercise-induced neurogenesis in the adult dentate gyrus," Proceedings of the National Academy 
of Sciences of the United States of America, vol. 104, no. 13, pp. 5638-5643, 2007.

[238] K. I. Erickson, M. W. Voss, R. S. Prakash et al., "Exercise training increases size of hippocampus and improves memory," Proceedings of the National Academy of Sciences of the United States of America, vol. 108, no. 7, pp. 3017-3022, 2011.

[239] S. A. Neeper, F. Gomez-Pinilla, J. Choi, and C. Cotman, "Exercise and brain neurotrophins," Nature, vol. 373, no. 6510, p. 109, 1995.

[240] L. T. Ferris, J. S. Williams, and C. L. Shen, "The effect of acute exercise on serum brain-derived neurotrophic factor levels and cognitive function," Medicine and Science in Sports and Exercise, vol. 39, no. 4, pp. 728-734, 2007.

[241] F. G. Coelho, T. M. Vital, A. M. Stein et al., “Acute aerobic exercise increases brain-derived neurotrophic factor levels in elderly with Alzheimer's disease," Journal of Alzheimer's Disease, vol. 39, no. 2, pp. 401-408, 2014.

[242] A. M. Stranahan, K. Lee, and M. P. Mattson, "Contributions of impaired hippocampal plasticity and neurodegeneration to age-related deficits in hormonal pulsatility," Ageing Research Reviews, vol. 7, no. 3, pp. 164-176, 2008.

[243] S. Vaynman and F. Gomez-Pinilla, "Revenge of the "sit": how lifestyle impacts neuronal and cognitive health through molecular systems that interface energy metabolism with neuronal plasticity," Journal of Neuroscience Research, vol. 84, no. 4, pp. 699-715, 2006.

[244] S. Vaynman, Z. Ying, and F. Gomez-Pinilla, "Exercise induces BDNF and synapsin I to specific hippocampal subfields," Journal of Neuroscience Research, vol. 76, no. 3, pp. 356-362, 2004.

[245] G. Gustafsson, C. M. Lira, J. Johansson et al., "The acute response of plasma brain-derived neurotrophic factor as a result of exercise in major depressive disorder," Psychiatry Research, vol. 169, no. 3, pp. 244-248, 2009.

[246] C. Laske, S. Banschbach, E. Stransky et al., "Exercise-induced normalization of decreased BDNF serum concentration in elderly women with remitted major depression," The International Journal of Neuropsychopharmacology, vol. 13, no. 5, pp. 595-602, 2010.

[247] M. S. Toups, T. L. Greer, B. T. Kurian et al., "Effects of serum brain derived neurotrophic factor on exercise augmentation treatment of depression," Journal of Psychiatric Research, vol. 45, no. 10, pp. 1301-1306, 2011.

[248] F. B. Schuch, M. P. Vasconcelos-Moreno, C. Borowsky et al., "The effects of exercise on oxidative stress (TBARS) and BDNF in severely depressed inpatients," European Archives of Psychiatry and Clinical Neuroscience, vol. 264, no. 7, pp. 605-613, 2014.

[249] S. Rojas Vega, H. K. Struder, B. Vera Wahrmann, A. Schmidt, W. Bloch, and W. Hollmann, "Acute BDNF and cortisol response to low intensity exercise and following ramp incremental exercise to exhaustion in humans," Brain Research, vol. 1121, no. 1, pp. 59-65, 2006.

[250] S. W. Tang, E. Chu, T. Hui, D. Helmeste, and C. Law, "Influence of exercise on serum brain-derived neurotrophic factor concentrations in healthy human subjects," Neuroscience Letters, vol. 431, no. 1, pp. 62-65, 2008.

[251] K. S. Krabbe, A. R. Nielsen, R. Krogh-Madsen et al., "Brainderived neurotrophic factor (BDNF) and type 2 diabetes," Diabetologia, vol. 50, no. 2, pp. 431-438, 2007.
[252] M. Lommatzsch, D. Zingler, K. Schuhbaeck et al., "The impact of age, weight and gender on BDNF levels in human platelets and plasma," Neurobiology of Aging, vol. 26, no. 1, pp. 115-123, 2005.

[253] P. Rasmussen, P. Brassard, H. Adser et al., "Evidence for a release of brain-derived neurotrophic factor from the brain during exercise," Experimental Physiology, vol. 94, no. 10, pp. 1062-1069, 2009.

[254] R. Staats, P. Stoll, D. Zingler, J. C. Virchow, and M. Lommatzsch, "Regulation of brain-derived neurotrophic factor (BDNF) during sleep apnoea treatment," Thorax, vol. 60, no. 8, pp. 688-692, 2005.

[255] S. L. Patterson, "Immune dysregulation and cognitive vulnerability in the aging brain: interactions of microglia, IL-1beta, BDNF and synaptic plasticity," Neuropharmacology, vol. 96, Part A, pp. 11-18, 2015.

[256] L. S. Schneider, F. Mangialasche, N. Andreasen et al., "Clinical trials and late-stage drug development for Alzheimer's disease: an appraisal from 1984 to 2014," Journal of Internal Medicine, vol. 275, no. 3, pp. 251-283, 2014.

[257] S. Colcombe and A. F. Kramer, "Fitness effects on the cognitive function of older adults: a meta-analytic study," Psychological Science, vol. 14, no. 2, pp. 125-130, 2003.

[258] P. J. Smith, J. A. Blumenthal, B. M. Hoffman et al., "Aerobic exercise and neurocognitive performance: a meta-analytic review of randomized controlled trials," Psychosomatic Medicine, vol. 72, no. 3, pp. 239-252, 2010.

[259] H. Makizako, T. Liu-Ambrose, H. Shimada et al., "Moderateintensity physical activity, hippocampal volume, and memory in older adults with mild cognitive impairment," The Journals of Gerontology. Series a, Biological Sciences and Medical Sciences, vol. 70, no. 4, pp. 480-486, 2015.

[260] K. A. Barbour, T. M. Edenfield, and J. A. Blumenthal, "Exercise as a treatment for depression and other psychiatric disorders: a review," Journal of Cardiopulmonary Rehabilitation and Prevention, vol. 27, no. 6, pp. 359-367, 2007.

[261] E. Ranjbar, A. H. Memari, S. Hafizi, M. Shayestehfar, F. S. Mirfazeli, and M. A. Eshghi, "Depression and exercise: a clinical review and management guideline," Asian Journal of Sports Medicine, vol. 6, no. 2, article e24055, 2015.

[262] Psychiatrists TRANZCo, Practice Guidelines for the Treatment of Patients with Major Depressive Disorder, N. G. Clearinghouse, Ed., 2010.

[263] H. A. Whiteford, L. Degenhardt, J. Rehm et al., "Global burden of disease attributable to mental and substance use disorders: findings from the Global Burden of Disease Study 2010," Lancet, vol. 382, no. 9904, pp. 1575-1586, 2013. 

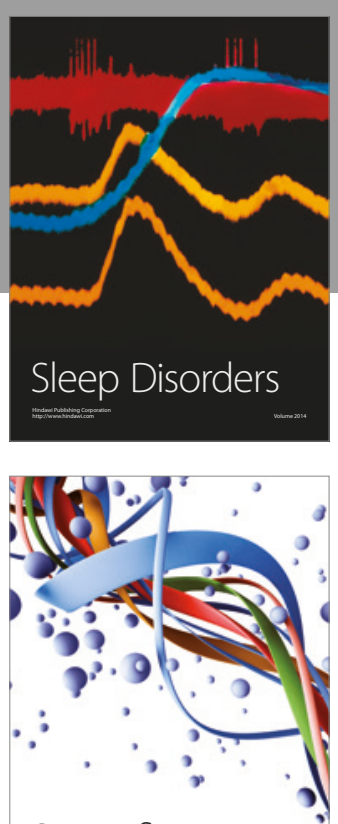

Scientifica
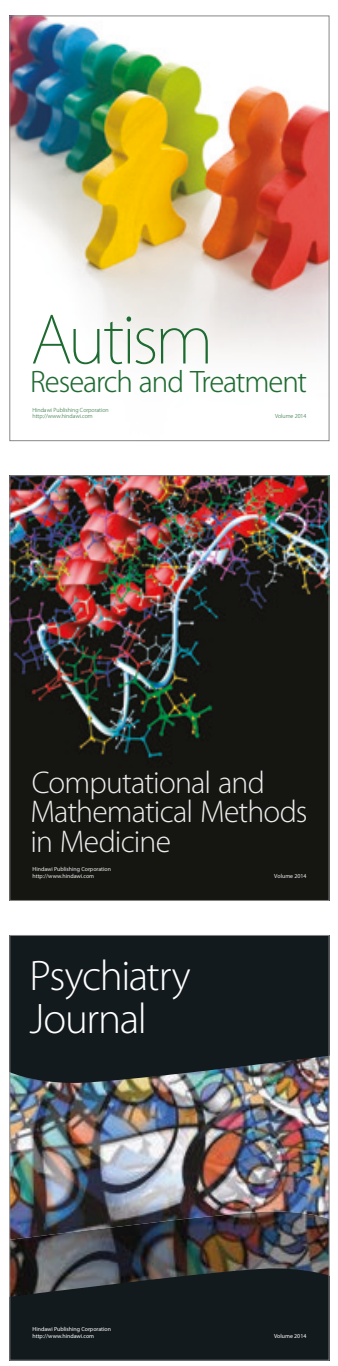
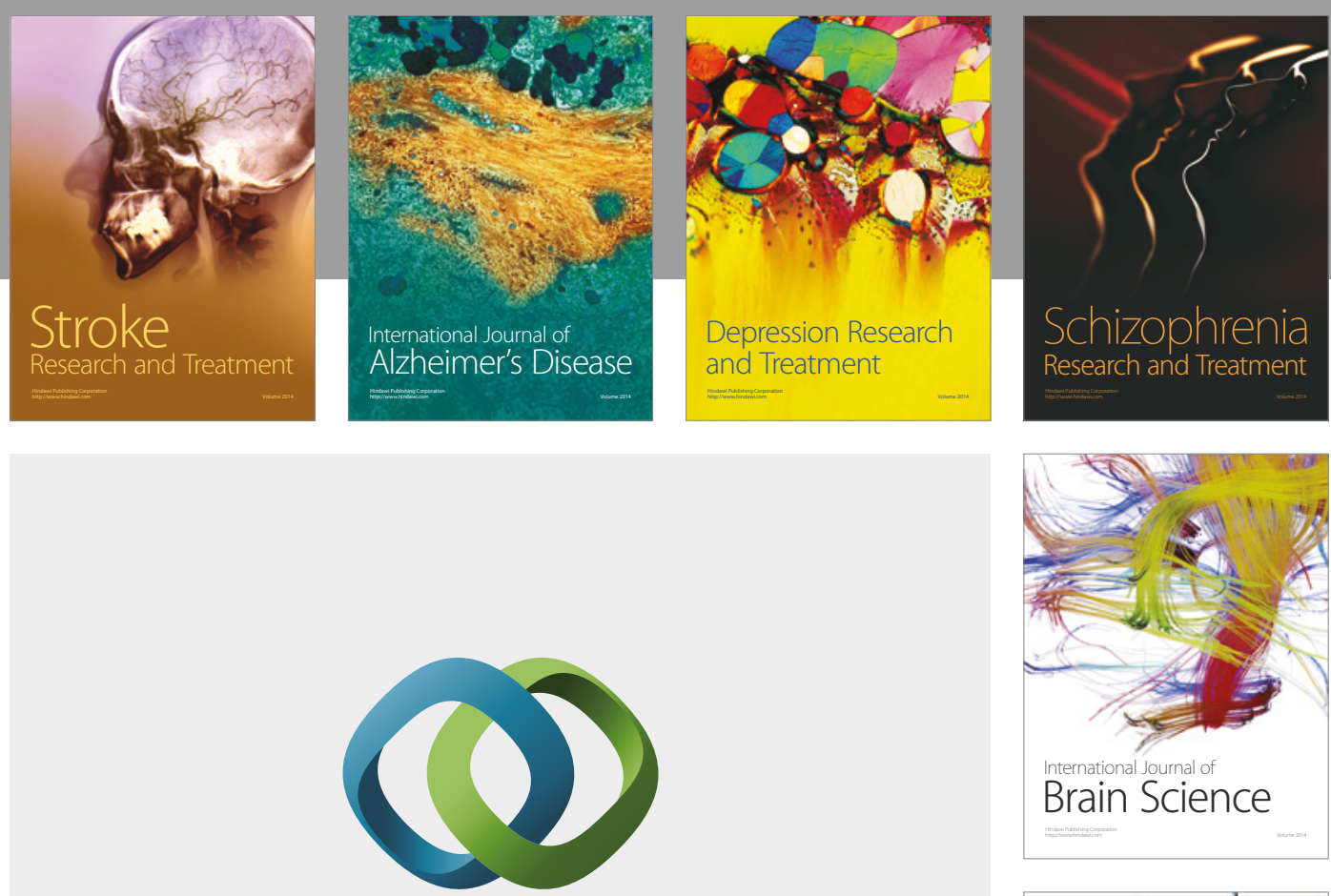

\section{Hindawi}

Submit your manuscripts at

https://www.hindawi.com
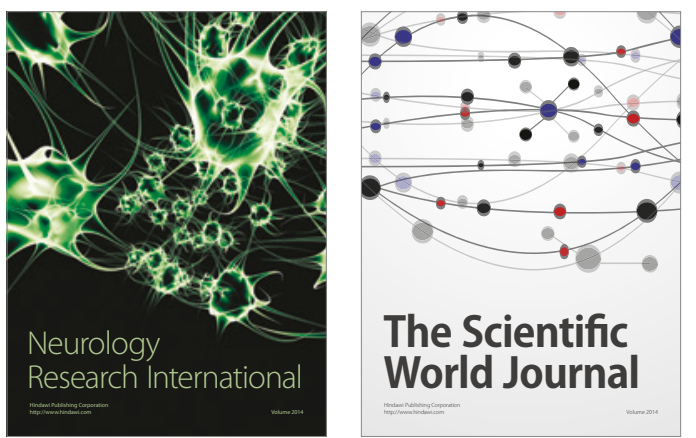

The Scientific World Journal

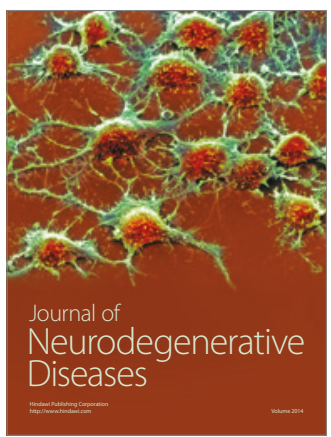

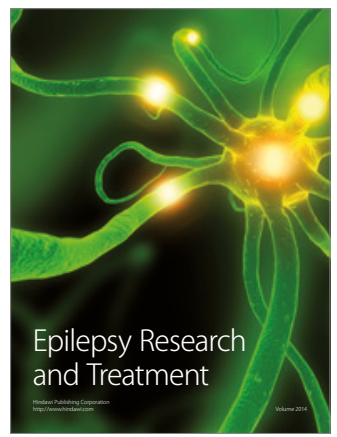

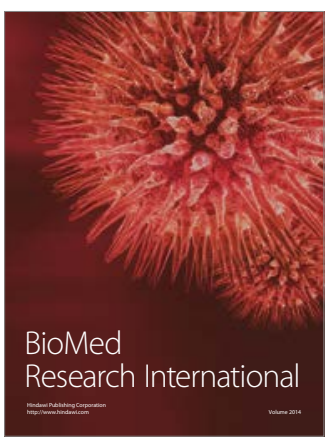

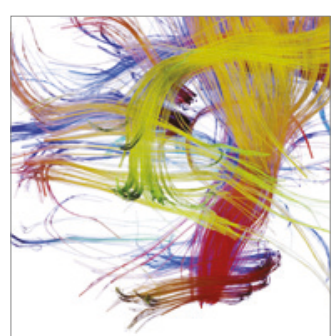

Brain Science

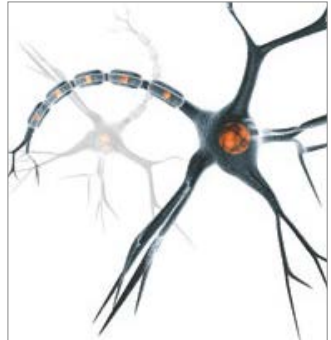

Neural Plasticity
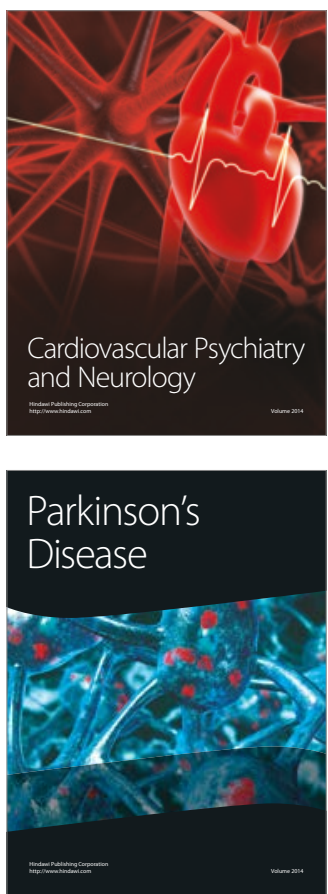